\title{
Traumatic Bonding and \\ Intimate Partner Violence
}

\author{
By \\ Vera George \\ 300152342 \\ Supervised by Professor Garth Fletcher
}

A thesis

submitted to the Victoria University of Wellington in

fulfillment of the requirements for the degree of

Master of Science

In Psychology

Victoria University of Wellington 


\section{Acknowledgements}

To my supervisor Prof Garth Fletcher who gave me guidance through it all

To my husband who gave me the only secure attachment I have ever had

To my mother who gave me the questions 


\section{TABLE OF CONTENTS}

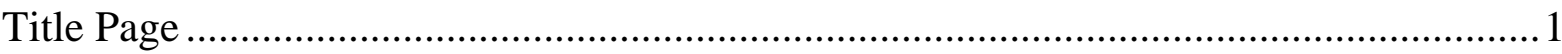

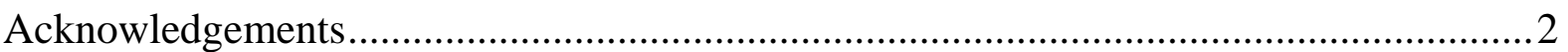

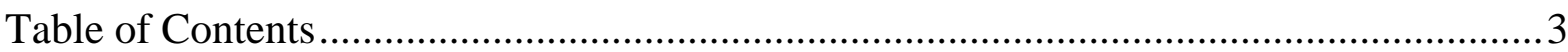

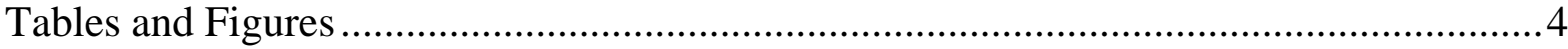

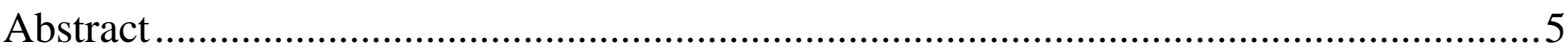

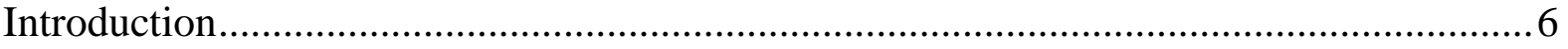

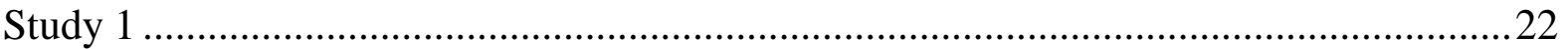

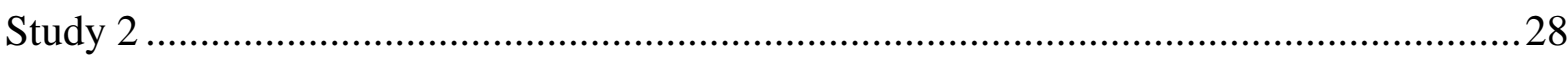

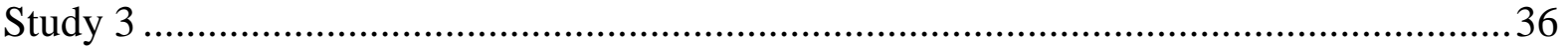

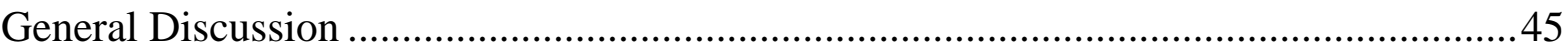

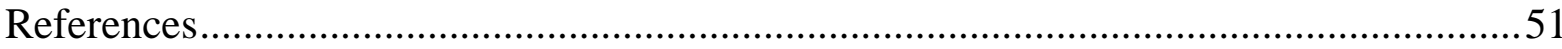

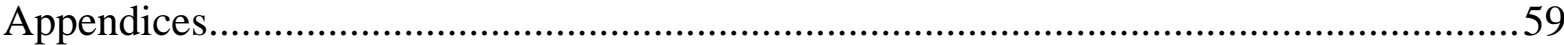




\section{TABLES AND FIGURES}

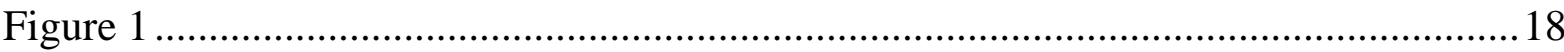

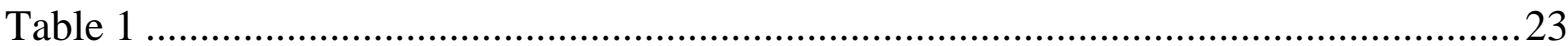

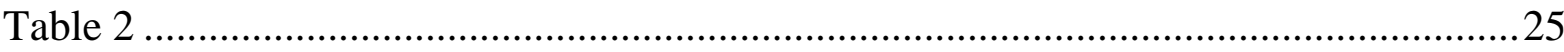

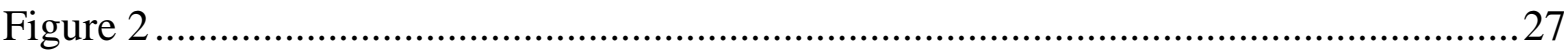

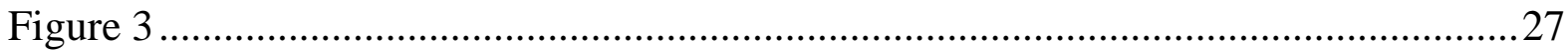

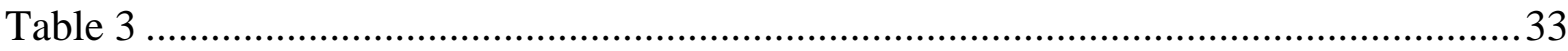

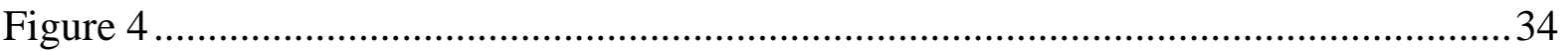

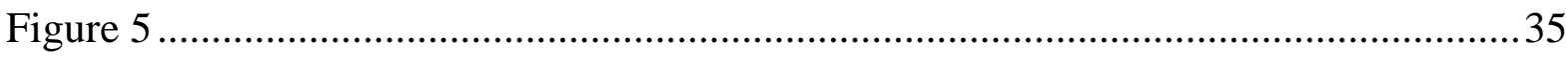

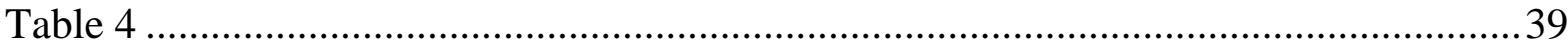

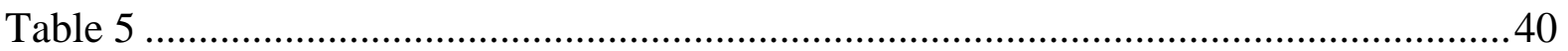

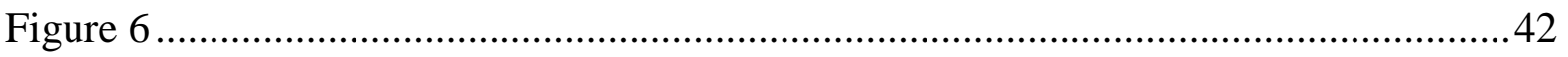

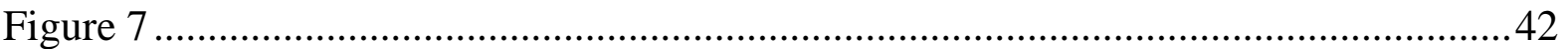

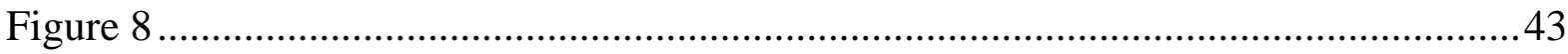




\begin{abstract}
Intimate partner violence is a pervasive and highly detrimental phenomenon. One common aspect of abusive relationships is a reluctance to leave one's partner. With this in mind, the current study explored the role of Stockholm syndrome in abusive relationships. Study 1 and 2 surveyed 508 diverse adults. Study 1 submitted the Stockholm syndrome scale to psychometric testing and confirmed a 3-factor solution for the scale. The three components are Core, justifying an abuser through cognitive distortions; Damage, ongoing psychological effects of abuse; and Love, the belief that one's survival depends on the love of an abuser. Study 2 tested the predictive qualities of the scale and found that its components are linked to relationship violence in a predictable fashion. These links may be moderated by insecure attachment. Study 3 analysed dyadic data from 86 couples and found positive associations between levels of Core and relationship violence, both within and across partners. Implications and future directions are discussed.
\end{abstract}


Traumatic Bonding and Intimate Partner Violence

"None are more hopelessly enslaved than those who falsely believe they are free." Goethe, Die Wahlverwandtschaften.

Intimate partner violence is a major health and criminal justice issue on a global scale (Abel, 2001). Although domestic violence has historically been trivialized or ignored, the costs of these abusive relationships can be measured in terms of loss of human life, serious injury, decline of physical and psychological wellbeing, and the consequences for children raised in such toxic environments. In addition to the human costs, there are significant economic costs to the individual, the family, and society as a whole (Snively, 1995).

In New Zealand, approximately half of all homicides are the result of family and intimate partner violence, with an average of 14 women, seven men, and 10 children losing their lives at the hands of a family member each year. In 2013 , there were 95,080 family violence incidents and offences recorded by police (Statistics New Zealand, 2014). As of 1995, it was estimated that the financial costs of family violence reached 1.2 billion dollars per year (Snively, 1995).

Much research has been undertaken in order to understand and find possible solutions to this major social and legal issue. Previous research has revealed the existence of multiple, repeat, and chronic victims of crime, including victims of intimate partner violence. Multiple victims of crime are those who experience two or more crimes in the space of 12 months, regardless of the type of offense, whereas repeat victims experience the same type of crime more than once in a 12 month timeframe. "Chronic victims" describes people who experience five or more crimes in one calendar year (New Zealand 
Ministry of Justice, 2010). Together, the crimes experienced by these three groups (multiple, repeat and chronic victims) capture $85 \%$ of all crime.

The New Zealand Crime and Safety Survey (New Zealand Ministry of Justice, 2010) found that victims of intimate partner violence are typically repeat victims, and $20 \%$ of these repeat victims become chronic victims. This small group (3\%) of victims experiences $88 \%$ of all intimate partner violence. A natural question often posed is why people stay in abusive and violent relationships. The current study attempts to answer this question by investigating some of the psychological features linked to intimate partner violence, with a particular focus on a form of traumatic bonding known as Stockholm syndrome.

A number of theoretical constructs and research underpin the current study, including attachment theory, pathological attachment in the form of traumatic bonding (i.e. Stockholm syndrome), cognitive dissonance theory, and prior work on the Stockholm syndrome scale.

\section{Attachment Theory}

Attachment theory, based on the work of John Bowlby and Mary Ainsworth (Bretherton, 1992), explains how the different attachment styles of infants continue into adulthood. Attachment theory was partly based on a study in which researchers observed the attachment styles of infant monkeys. The young monkeys were isolated from their mothers at birth and were given mechanical "mothers" with or without a terry cloth covering (Bowlby, 1977). The researchers noted that the baby monkeys preferred the terry clothed mother even when it was not a source of food. This led the researchers to conclude that bonding with a caregiver was an innate need and was attributable to 
evolutionary processes that had developed to facilitate survival, i.e. ensuring proximity to a caregiver.

Ainsworth (1970) later carried out observational studies on the interactions between human toddlers and their mothers. The mothers would enter and leave the room for a few minutes at a time, interchanging with strangers. This was intended to replicate interactions with familiar and unfamiliar figures in the child's life. Observations were based on the toddlers' reactions to the mothers' unexpected exits and returns. From these observations, three main attachment types were identified: secure, avoidant, and anxious.

Children of the secure attachment type (70\% of the sample) regarded their mothers as a "secure base" from which they could explore the world and return to at any time. The securely attached child would interact with the stranger in the presence of his or her mother but not in her absence. This child would show moderate distress when his or her mother left the room but be positive and happy on her return. It was determined that a secure attachment was created by a primary caregiver who was sensitive to the signals of the infant and responded to his or her needs appropriately and consistently.

Avoidantly attached infants ( $15 \%$ of the sample) would play with the stranger with or without the presence of their mothers, showed little interest in the exit or return of their mothers, and were able to be soothed by either the stranger or their mothers. Avoidant attachment was produced by a neglectful caregiver who was emotionally and/or physically unavailable to tend to the child's needs, to the point of even ignoring the child's needs. Such caregiving produced a very detached and independent child.

The third, anxious attachment type (15\% of the sample) exhibited a mix of distressed behaviours. The anxiously attached child showed extreme levels of distress when his or her mother left the room but, on her return, would display unusual behaviour 
such as such as clinging to and hitting his or her mother at the same time. These children would cry far more and explore less than securely or avoidantly attached children. This was usually a response to intermittent caregiving, i.e. a caregiver who was not consistent in attending to his or her child's needs.

Shaver, working with Hazan (Hazan \& Shaver, 1987), and Mikulincer (Mikulincer \& Shaver, 2007) made the first steps to extend attachment theory from infants to adult romantic relationships by noting 17 features that are present in both types of bonding. These features include, among others, eye contact, physical affection, playing together, distress on separation, and feeding each other (Fletcher, Simpson, Campbell, \& Overall, 2013). This theory sparked the creation of a huge body of literature with hundreds of studies replicating the finding of three distinct attachment styles (Mikulincer, 2007). These styles can be subdivided into secure or insecure (anxious or avoidant) styles, which roughly correspond to the infant attachment styles previously mentioned (Ainsworth \& Bell, 1970; Bowlby, 1977).

A securely attached adult ( $\sim 60 \%$ of the general adult population) has struck a golden balance between closeness and independence and is more likely to express high levels of commitment to his or her relationship (Frei \& Shaver, 2002). Securely attached adults also experience better health and survival (Beckes \& Coan, 2013), less conflict (Campbell, Simpson, Boldry, \& Kashy, 2005), fewer depressive symptoms (Lee \& Hankin, 2009), and more coping skills in the face of stressful events (Berant, Mikulincer, Shaver, \& Segal, 2005). An adult with a secure attachment views one's self, partners, and relationships in a relatively positive light.

The anxious, insecurely attached adult ( $20 \%$ of the general adult population) demands extreme levels of intimacy from his or her partner (often unreciprocated) and 
constantly seeks approval and responsiveness. This may result in an overly dependent relationship. These individuals have issues regarding trust in their relationships, are extremely emotionally expressive (which may border on hysteria), and show high levels of impulsiveness. They also tend to have less favourable views of themselves and their partners (Mikulincer \& Shaver, 2007).

The avoidant, insecurely attached adult ( $20 \%$ of the general adult population) desires such high levels of independence as to appear undesiring of a relationship at all. Theses adults feel uncomfortable with close relationships and may even deem them unnecessary. An avoidantly attached adult's typical response to any stressful event in his or her relationship is to distance him- or herself from one's partner, whom he or she typically holds in poor regard (Mikulincer \& Shaver, 2007). Fortunately, attachment styles are not static and can evolve over time (Letherby, 2008).

\section{Traumatic Bonding}

Insecure attachment theory also provides insight into traumatic bonding. Dutton and Painter (1993) suggested that intermittent abuse corresponds to a traumatic bonding type of attachment. This theory may explain how repeat victimisation as well as a number of risk factors (e.g. addictions, social skills deficits, anger) combine to produce an extreme insecure attachment style. Dutton and White (2012) argued that many predictors of intimate partner violence are actually symptoms of an insecure parent-child attachment, which in turn is a strong predictor of intimate partner violence.

This theory was developed from the same type of experiment that formed the basis for attachment theory. Following Ainsworth's (1970) experiment, Harlow and Soumi (1970) isolated infant monkeys to be reared by mechanical mothers. However, the purpose was not to observe attachment styles but to induce psychopathology in monkeys. 
This research was clearly unethical and cruel in the extreme, but it did provide a basis for understanding Stockholm syndrome. Terry clothed mothers were also used with the isolated baby monkeys, but these mechanical mothers were programmed to subject the infant monkeys to horrific abuse. The abuse ranged from blasting the infants with compressed air under high pressure to shaking them until their teeth rattled. Some mothers were programmed to slam the infant into a wall, and others even protruded brass spikes from their bodies. In every case, the infant monkeys would rush back to cling to the mothers at the first opportunity, regardless of the abuse to which they had been subjected. The only way to prevent the infant monkeys from clinging to the mothers was continuous punishment or an available alternative.

Harlow and Soumi (1970) argued that that this bond was a survival defence mechanism in which the baby monkeys were driven to bond with a caregiver, even an abusive one, as survival was dependent on that bond. By alternating the "affection" of the cloth mother (covered with the soft terry cloth material) with punishment (the intermittent abuse), an extremely potent form of traumatic bonding was created; the more the monkeys were abused, the more attempts they made to bond. The authors concluded that they had found a technique not for inducing psychopathology but for enhancing an extreme form of maternal attachment. Stockholm syndrome, similarly, can be viewed as a type of traumatic bonding.

\section{Stockholm Syndrome}

The term Stockholm syndrome was coined in 1973 by Bejerot, who used the term to describe the enigmatic behaviour of three women and one man who were held hostage for six days in the vault of a bank in Stockholm, Sweden (Bejerot, 1974). These hostages developed an emotional bond with their captors that was so strong that they threatened the 
officials who were trying to help them. The captives refused to leave the vault before the captors, fearful that the police would harm the captors. This bond (also known as capture, traumatic, or terror bonding) continued long after the release of the hostages, including scenes of the captives kissing and hugging their captors once freed from the vault. Reports that two of the female hostages were romantically involved with two of the captors surfaced some months later (Graham, 1994). This seemingly paradoxical response has also been seen in other contexts and populations, specifically concentration camp prisoners, prisoners of war, civilians held in Chinese Communist prisons, cult members, abused children, incest victims, and pimp-procured prostitutes (Graham, 1994).

Graham (1995) developed the Stockholm syndrome theory, specifically linked to intimate partner violence, based on the psychology and behaviour of these groups. She argued that four precursors were necessary for the development of Stockholm syndrome: perceived threat to survival, perceived kindness, isolation, and the perceived inability to escape. Stockholm syndrome represents a defence mechanism for coping with these factors, including cognitive and perceptual distortions. Sixty-six items were listed by Graham (behaviours, attitudes, and beliefs) as being linked to the syndrome (see Appendix A for a list of these aspects as printed in Graham, 1994). Based on these items, Graham developed a 49-item scale to measure Stockholm syndrome in relationships, a modified version of which was used in the current study.

In the original scale, Graham (1995) found that the items were largely represented by three factors: core Stockholm syndrome, psychological damage, and love dependency. Core Stockholm syndrome contained aspects central to Stockholm syndrome theory and described cognitive distortions and interpersonal trauma. These included rationalizing and/or minimizing a violent partner's behaviour, self-blame, and reporting love in the 
context of fear. Psychological damage captured depression, low self-esteem, and other interpersonal difficulties. Love dependency was typified by a strong belief that one's very survival depended on a partner's love, extreme idolization, and the belief that without one's partner there would be nothing for which to live.

The diagnostic criteria of traumatic bonding, terror bonding, or Stockholm syndrome are not listed in the Diagnostic and Statistical Manual of Mental Disorders (DSM-V). As such, there is no official consensus on the definition of traumatic bonding, and this may account for the dearth of empirical studies on this topic (Reid, Haskell, Dillahunt-Aspillaga, \& Thor, 2013). In point of fact, very few empirical studies regarding traumatic bonding and intimate partner violence have been published in the last 15 years, and only one administered Graham's (1995) Stockholm syndrome scale.

Demarest (2009) interviewed 50 women seeking refuge at women's shelters. The main hypothesis of this study was that post-traumatic stress disorder and Stockholm syndrome would be positively correlated as a result of the similarities of avoidance coping in both conditions. Although this hypothesis was not supported, an interesting (albeit non-significant) pattern was revealed after analyses of the Stockholm syndrome scale, post-traumatic stress disorder, and women abuse scale. Specifically, when low scores of Stockholm syndrome were recorded, a correlation between post-traumatic stress disorder and abuse was also likely to be found. It was suggested that Stockholm syndrome might have actually moderated the relationship between post-traumatic stress disorder and abuse in some way, despite not being explicitly correlated with either condition. The fact that only women who had actually left an abusive relationship were studied, as well as small sample size and lack of prior research supporting the scales used, was cited as a possible explanation for the lack of significant correlations. However, the 
internal reliability of the Stockholm syndrome components correlated highly with the total score of the Stockholm syndrome scale, with a Pearson's $r$ of .965 (Core); .915 (Damage); and .841 (Love), $p<.01$. for all three components. Cognitive dissonance theory can help explain some aspects of Stockholm syndrome, which I now turn to.

\section{Cognitive Dissonance Theory}

Cognitive dissonance theory was first synthesised by Leon Festinger in his book, A Theory of Cognitive Dissonance (1957). The title is an apt description of the theory as "cognitive" describes the mind (or thinking) and "dissonance" is defined by conflict or incongruity. Hence, cognitive dissonance is present when two or more conflicting or incongruous beliefs are held simultaneously or when new information is presented that conflicts with existing beliefs. Cognitive dissonance creates an uncomfortable psychological state, which then motivates strategies to reduce this discomfort (Festinger, 1957, 1962).

Applying these ideas to intimate partner violence, imagine that Tom is regularly physically and emotionally abused by his wife, Sue. Tom holds the belief that good marriages are not abusive. Tom also believes that he has a good marriage. The conflict between such cognitions and reality creates cognitive dissonance for Tom, which he may alleviate in one of the four following ways:

- Tom can change his cognition about his marriage and accept that it is not a good and healthy marriage. He might think, "I am not in a good marriage after all."

- Tom can justify the reality of the abuse by changing the conflicting cognition. He might rationalize his situation by thinking, "My wife abuses me because I 
deserve it, not because our marriage is bad." Note that this captures the Core construct of Stockholm syndrome.

- Tom can find justification for the abuse by adding new cognitions, such as: "My wife's love and protection are more important than any hurt she may cause me." Note that this is an item from the Love component of the Stockholm syndrome scale.

- Tom may unequivocally deny any information that conflicts with his belief that he has a good marriage by thinking: "My wife does not abuse me. She is a good wife; this behaviour shows commitment, and I have a good marriage." Any of these four responses would reduce cognitive dissonance with varying consequences for Tom and his relationship.

Investment in the relationship also plays a critical role. For example, if Tom is financially dependent, uneasy about the impact of divorce on the children, overly concerned about loss of status due to divorce, or worried about the stigma from seeking counselling, he is far more likely to reduce dissonance by justifying, adding new cognitions, or denying abuse than admitting that his marriage is not healthy (perceived inability to escape as outlined in Graham, 1994). However, if Tom has less time, emotion, and resources invested in the relationship, he is more likely to terminate or at least reassess the marriage (Fletcher et al., 2013; Harmon-Jones, Brehm, Greenberg, Simon, \& Nelson, 1996). Attachment style, traumatic bonding and Stockholm syndrome, are the theoretical constructs which the current study is examining in relation to intimate partner violence. Several forms of intimate partner violence have been identified. It is useful to examine these as they explain the types and forms of violence seen in this study. These will now be explored in turn. 


\section{Intimate Partner Violence}

The reporting of intimate partner violence, in terms of incidence, prevalence, and gender symmetry (whether males or females are more likely to be perpetrators of intimate partner violence) is a subject of much contention, as very different figures are regularly presented in the media. This stems largely from the differential definitions, samples and methods implemented to measure intimate partner violence, which inevitably yield differential results (Berns, 2004; Johnson \& Ferraro, 2000; Ramsay, 2002). Not surprisingly, different samples and methods used to measure intimate partner violence yield different results. Research from court records and shelters show that intimate partner violence is rare but serious and almost exclusively male-perpetrated. Community samples, on the other hand, show that intimate partner violence is common, rarely serious, and perpetrated equally by both men and women (Frye \& Karney, 2006; GrahamKevan \& Archer, 2003; Johnson \& Leone, 2005).

Johnson's typology. Johnson (2008) created a popular typology to explain these apparent inconsistencies and differentiate between types of intimate partner violence. The extreme type of intimate partner violence found at women's refuges and in court records is called Intimate Terrorism (originally Patriarchal Terrorism). The key feature of this form of intimate partner violence is an ongoing pattern of power and control. Indeed, this part of Johnson's typology is based on the Power and Control wheel created with the help of women who sought refuge at women's shelters (Mills, 2008; see Figure 1). Violence is what holds everything together, a means to achieve the goal of control. In fact, the threat of violence on its own may be enough to control the partner relationship.

Violent resistance. It is part of human nature to resist and retaliate. Some individuals, when faced with an intimate terrorist, will resort to violent resistance. This 
may be in self-defence, revenge, or retaliation. In this case, the individual is violent but not controlling. This is the basis for the "Battered Spouse Defence," which has been used in cases of physically and psychologically abused spouses who have killed their abusers (Walker, 2009) and has received much media attention. In very rare cases, two individuals may be in a relationship and both will meet the criteria for intimate terrorism. This is known as mutual violent control. Very little is known about the dynamics of such a relationship due to its rarity. The vast majority of those perpetrating intimate terrorism are males, and the vast majority of those perpetrating violent resistance are female.

Situational couple violence. Johnson (2008) found that, in community samples, a less extreme form of violence, termed situational couple violence, was typically being measured. This type of violence (whilst unhealthy and repugnant) is not about the control of a relationship. Rather, it is brought on - as the name suggests - by a particular situation. The situation may be as benign as not agreeing which channel to watch on the television or where to go on holiday. Although this type of intimate partner violence can escalate into serious or even lethal forms (sometimes resembling intimate terrorism, violent resistance, or mutual violent control), in general, this type of intimate partner violence does not require medical or legal services. Indeed, the couples engaging in such behaviour may consider it wrong but not criminal. This form of intimate partner violence is apparent in community samples. 


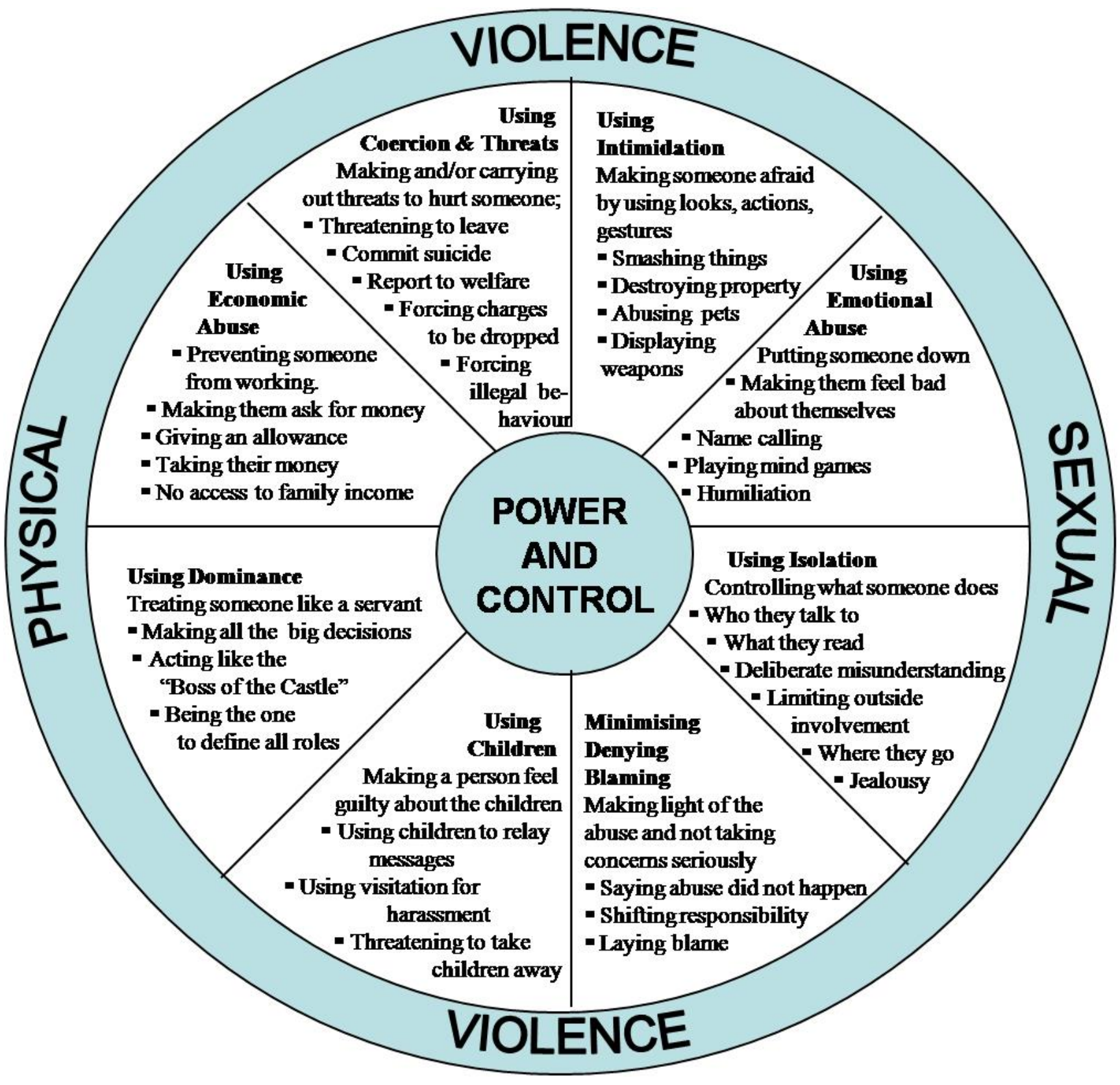

Figure 1. The power and control wheel (Mills, 2008). 


\section{Conflict Tactics Inventory}

The conflict tactics inventory (Straus, 2007), which was used in the current study, is the most widely used instrument employed to measure the frequency of intimate partner and family violence. It has been cited thousands of times in reputable, peer reviewed journals since its creation in 1979 . The underlying theory behind the conflict tactics inventory posits that it is the inability to calmly resolve conflicts that inevitably arise in relationships that is largely responsible for intimate partner violence. This position also claims that intimate partner violence is gender symmetrical, with males and females being equally likely to report self- or partner-violence (Straus, 1979).

The conflict tactics inventory measures incidents of physical aggression experienced by participants in the previous 12 months (see Appendix B for a list of all scales and items used in this study). As previously noted in Johnson's typology, violence may be only a small part of an abusive relationship. However, for the purposes of the current study, measurements of other forms of abuse (emotional, financial, coercion, etc.) have been omitted for four reasons.

First, as briefly discussed, many victims of intimate partner violence may not consider that what they are experiencing is abuse. By measuring only behavioural incidents of physical aggression, the onus of cognitively appraising one's relationship is removed. Second, the conflict tactics inventory has shown excellent reliability, internal consistency, temporal consistency, and content and construct validity in hundreds of studies (Straus, 2007). Third, the conflict tactics inventory can be administered quickly and at very low cost, making it ideal for this study. Finally, the conflict tactics inventory has found gender symmetry in the frequency of intimate partner violence in over 200 studies (See for example: Archer, 2002; Arias \& Johnson, 1989; Arriaga \& Foshee, 2004; 
Billingham \& Sack, 1986; Brinkerhoff \& Lupri, 1988; Ehrensaft, Moffitt, \& Caspi, 2004; Gryl, Stith, \& Bird, 1991).

In the current study, the participants were drawn from the general community rather than constituting a clinical sample. In these kinds of samples, there is evidence that most of the intimate partner violence fits within what Johnson termed situational couple violence, which tends to be dyadic and less severe in nature. For this reason, I predicted that relatively low levels of intimate aggression would be found, with no gender differences in the reported frequency of intimate partner violence.

For the purposes of this study, a slightly modified version of the conflict tactics inventory (Straus, 1979), which was also implemented in Graham (1995) and George (2013), was used. Graham reported that those with higher scores on the Stockholm syndrome scale had higher rates of partner-reported violence. George replicated these findings and also found a high correlation between self-reported and partner-reported violence $(r=.69, p<0.1)$ with no significant gender differences.

Graham's (1995) initial study had several limitations. First, it was limited to female university students studying introductory psychology in the United States of America, and secondly, the Stockholm Syndrome Scales contained several very similar items on each component which possibly skewed the internal consistency reliability of the scale. George (2013) addressed these issues by including both males and females across a broad age and educational status range and residing in ten countries. The Stockholm syndrome scale was also shortened by identifying the 27 highest loading items from the original 49 items for each subscale (Core, Damage, Love), thus removing items that were essentially repetitive. The three factors are: Core Stockholm Syndrome ("Core" - alliance with the abuser and justification of the abuse), Psychological Damage ("Damage" - 
lasting psychological effects stemming from the abuse), and Love-Dependency ("Love" the extent to which victims feel they love or are dependent on their abusers). Pronouns were also changed to be more gender neutral and inclusive.

George (2013) found that an exploratory factor analysis revealed a clean 3-factor solution for the Stockholm Syndrome Scale, supporting the findings of Graham (1995). Higher scores on the Stockholm syndrome scale were associated with higher levels of self- and partner-reported violence. The Core component of Stockholm syndrome explained most of the variance in reported violence whereas Damage and Love explained less.

\section{Current Research}

The current research expanded on George (2013) and had three main objectives. First, the validity and internal consistency of the Stockholm syndrome scale was further assessed using a confirmatory factor analysis. Second, the predictive validity of the Stockholm syndrome scale was measured. Finally, preliminary evidence was gathered concerning the dyadic effects within couples in a romantic relationship.

Three studies were conducted. In study 1, a confirmatory factor analysis was conducted to examine the internal reliability and the factorial structure of the Stockholm syndrome scale. Study 2 tested the moderating effects of anxious and avoidant attachment between components of the Stockholm syndrome scale and reported partner aggression. Study 3 examined the within-partner and across-partner correlations of the Stockholm syndrome scale and reported partner aggression in a sample of couples. A structural equation modelling approach using the interdependence model was implemented. 


\section{Study 1}

The Stockholm syndrome scale was developed from an original pool of items from Graham et al. (1995), into a 24-item scale, with eight items for each component (Core, Damage, Love). This scale was initially piloted with an international online sample by George (2013). Statistical checks for internal reliability and an exploratory factor analysis were carried out. As expected, a factor analysis revealed a clean 3-factor solution for the Stockholm syndrome scale in 2013. The current study further tested the reliability and replicability of the Stockholm syndrome scale and conducted a confirmatory factor analysis. I hypothesised that a solution would be obtained with three relatively independent but correlated factors, supporting the prior findings of Graham et al. (1995), Demarest (2009), and George (2013).

\section{Method}

\section{Participants.}

Initially, 610 participants contributed to this study via an online survey. The data from 102 participants were excluded because the participants were a) under 18 years of age, b) failed to complete the entire survey, or c) failed to give the appropriate response to the item that checked attention (see Materials and Procedure). The data from the remaining 508 participants (240 male and 268 female) were analysed for the current study. Participants were recruited from Western first world countries, with the majority $(49.8 \%)$ residing in the United States of America (see Table 1). 
Table 1

Country of Residence of Participants

\begin{tabular}{lc}
\hline Country of Residence & \% of Sample \\
\cline { 2 - 2 } United States of America & 49.8 \\
Canada & 21.1 \\
United Kingdom & 17.7 \\
Germany & 5.7 \\
Australia & 2.4 \\
New Zealand & 1.2 \\
Ireland & 0.8 \\
Finland & 0.8 \\
Scotland & 0.6 \\
\hline
\end{tabular}

Ages of participants ranged from 18 to 80 years $(M=37.9$ years, $S D=11.7$ years $)$ with $75 \%$ of the sample aged 45 years or less. The relationship status of the sample was $44.8 \%$ married, $25.1 \%$ cohabiting, and $30 \%$ dating. The length of the relationships ranged from 1.17 years to 27.08 years $(M=6.03$ years, $S D=5.45$ years $)$ with $50 \%$ of the sample indicating that they had been in a relationship from 4.25 years to 7.06 years. The overwhelming majority of the sample (95\%) identified as heterosexual.

\section{Materials}

Stockholm syndrome scale. This scale measures three components of Stockholm syndrome (Graham et al., 1995): Core, Psychological Damage (Damage), and Love Dependency (Love). The original study used 49 items (Graham et al., 1995), which were reduced to 24 in subsequent research (George, 2013) to limit participant fatigue and dropout rates (Galesic \& Bosnjak, 2009). The items were selected based on how strongly they loaded onto each component of Stockholm syndrome in the original study. Weakly correlated and repetitious items were removed. For the current study, pronouns were also changed from masculine to gender neutral so as not to presume the sex of a victim or abuser. Example items on this scale were: "If I give my partner enough love, s/he will stop 
getting so angry at me" (Core); "I cannot make decisions" (Damage); "My partner's love and protection are more important than any hurt s/he might cause me" (Love).

Respondents replied on a 7-point Likert scale from 1 (I NEVER feel this way) to 7 (I ALWAYS feel this way). See Appendix B for a list of all scales and items used in this study.

Evaluation of attention. An attention question was used in order to determine if respondents were thoroughly reviewing each question and not randomly replying. The question was: "Are you paying attention? If you are, reply 'Extremely." Participants who did not respond "Extremely" were removed from the dataset.

\section{Procedure}

Participants were recruited using Amazon Mechanical Turk, a crowdsourcing Internet marketplace that hires individuals for small online tasks. For the purposes of the current study, respondents were asked to fill out a survey on an online survey platform (Finley, 1999) and were rewarded with \$0.40 USD each. Prior to completing the survey, participants were informed of their right to withdraw from the study at any time. Survey responses were anonymous in order to protect respondents' identities. Ethical approval for the current study was granted by the Victoria University of Wellington Human Ethics Committee. All participants were thanked for their time and debriefed after finishing the survey. 


\section{Results}

\section{Descriptive Results.}

The means for Core, Damage, and Love were moderate. The means and standard deviations for the three components of the Stockholm syndrome scale are shown in Table 2.

Table 2

\begin{tabular}{lcc} 
Means and Standard Deviations of Total Scores by Stockholm Syndrome Scale Component \\
\hline Component & $\underline{M}$ & $\underline{S D}$ \\
Core & 2.41 & 1.35 \\
Damage & 2.91 & 1.19 \\
Love & 3.00 & 1.29 \\
\hline
\end{tabular}

\section{Correlations.}

All three components of the Stockholm syndrome scale were moderately and positively correlated with each other. Core and Damage had a correlation of $r=.407$ ( $p<$ 0.01), Core and Love had a correlation of $r=.384(p<0.01)$, and Love and Damage had a correlation of $r=.194, p<0.01$.

\section{Confirmatory Factor Analysis.}

Data for confirmatory factor analyses were analysed using the software programme AMOS. In order to make a meaningful comparison between the overarching construct of the Stockholm syndrome scale and the three subscales (Core, Damage, and Love) as well as to facilitate analysis, each subscale was split into three parts and summed to form three observed variables for each component of the Stockholm syndrome scale. Levels of fit were evaluated using the significance levels of the robust chi-square, the comparative fit index (CFI), and the root mean square error of approximation (RMSEA). The CFI has the advantage of not being negatively affected by sample size and a good fit 
is deemed to be a result of .90 or higher (Bentler, 1995). The CFI is regarded as a superior measure of fit compared to the traditional statistical significance level, which is predisposed to producing conservative estimates of fit when faced with evaluating many variables and is acutely sensitive to sample size (Marsh, Balla, \& McDonald, 1988). The RMSEA provides a measure of relative discrepancy per degree of freedom. An RMSEA value of .08 or lower is considered a reasonable fit (Browne \& Cudek, 1993).

The first model tested can be seen in Figure 2. In this model, the three divisions of each component were treated as all loading onto a single factor. This model showed a poor fit with a CFI of .567. Although the RMSEA of .267 is normally considered an acceptable fit, the chi-squared distribution $(\chi 2(27)=1001.02, p<.000)$, in conjunction with the low CFI, showed that it was not in this case.

The second model tested (see Figure 3) treated the three divisions of each component as loading onto a single component while allowing the three components to be correlated. This model showed a much better fit than the first model, with a CFI of .96 and a RMSEA of .084, only marginally over the recommended threshold of .08 . The chisquared distribution $(\chi 2(24)=109.42, p<.001)$ and the difference in fit $(\chi 2(3)=891.73$, $p<.001)$ conclusively supported the superior fit of this model. 


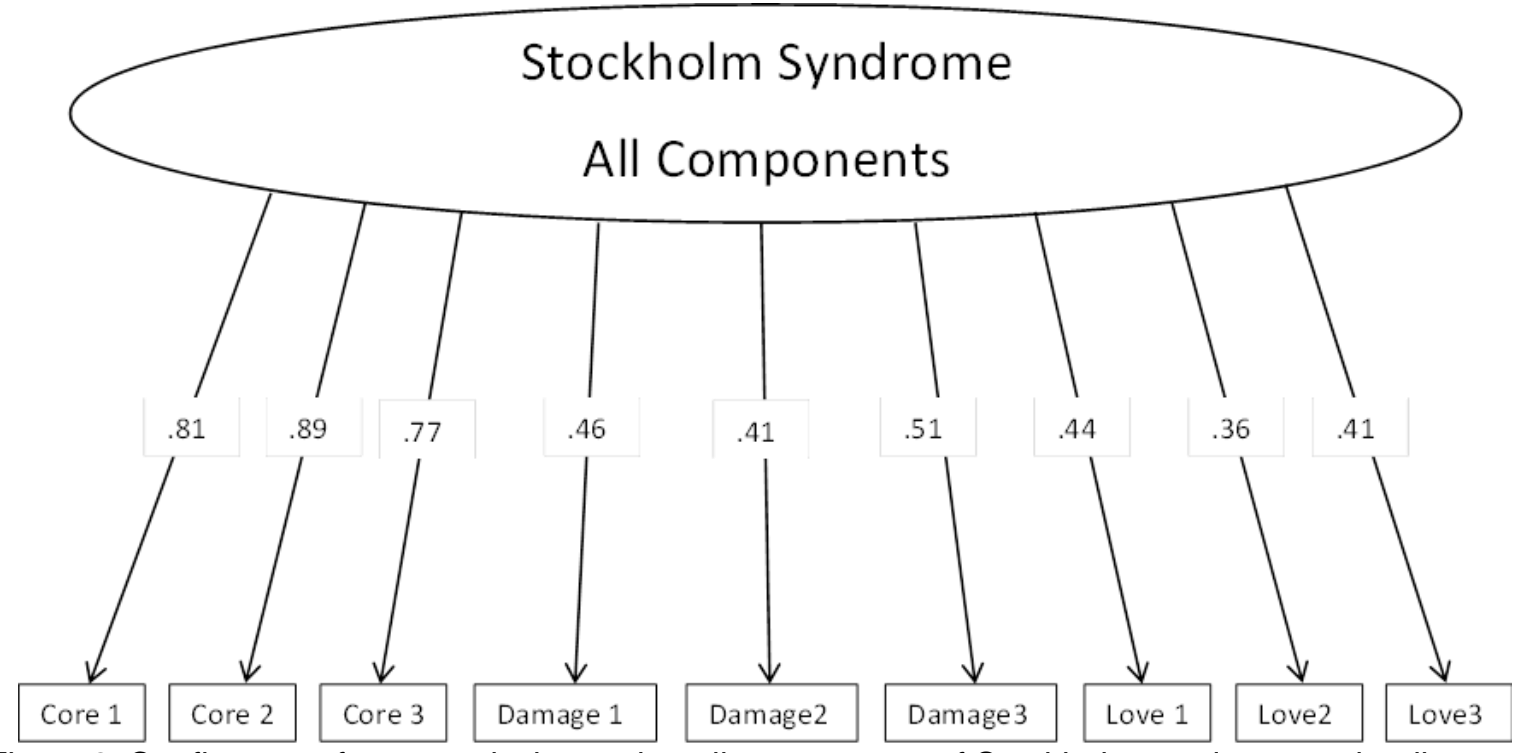

Figure 2. Confirmatory factor analysis treating all components of Stockholm syndrome as loading onto a single factor.

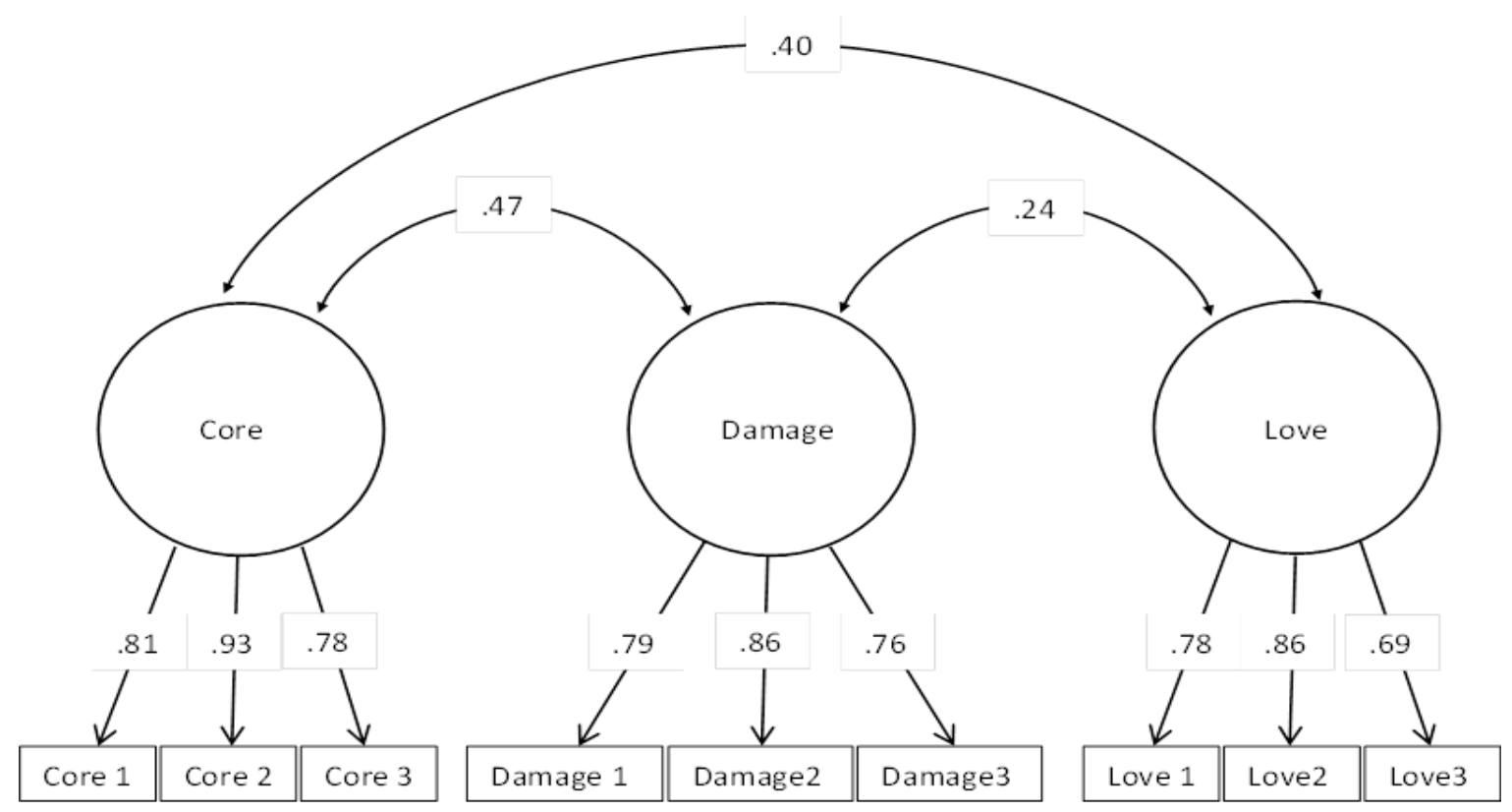

Figure 3. Confirmatory factor analysis treating Stockholm syndrome as three distinct but correlated measures. 


\section{Discussion}

The inter-factor correlations between Core and Damage and between Core and Love were moderate, while the inter-factor correlation between Core and Love was more modest. This shows that, as predicted, these three factors are not completely independent but contribute to an overarching construct of Stockholm syndrome. The data supported the hypothesis that the Stockholm syndrome scale is composed of three correlated but independent factors, as shown in Figure 3. The tripartite model also showed an acceptable CFI score and a marginally acceptable RMSEA score.

The results from the confirmatory factor analysis clearly indicated the existence of three separate factors that were reliable and internally consistent. Each observed variable revealed moderately high and positive loadings onto each factor as shown in Figure 3. These results are consistent with previous findings (George, 2013).

Comparisons between the two models (tripartite and single-factor) revealed large differences in fit. The first, single factor model (see Figure 2) provided a poor fit for the data. Although the RMSEA of the 1-factor model would customarily be considered acceptable, the CFI and Chi-square, particularly when compared to the 3-factor model, conclusively supported the superior fit of the tripartite model (see Figure 3).

\section{Study 2}

Study 2 assessed the predictive validity of the Stockholm syndrome scale. The general hypothesis was that higher levels of intimate partner violence would be linked to higher scores on the Stockholm syndrome subscales. Specifically, it was hypothesised that Core subscale scores would moderately predict intimate partner violence scores, in keeping with previous research (Demarest, 2009; George, 2013; Graham et al., 1995). Predictions regarding the connections between aggression and the Love and Damage 
components were not as clear cut due to the lack of previous research in these areas. Analyses of these links were largely exploratory.

Study 2 also explored the moderating effects of insecure (anxious, avoidant) attachment on the links between the Stockholm syndrome components and intimate aggression. The second hypothesis predicted that insecure attachment would moderate the link between the Stockholm syndrome scale and intimate partner violence. Specifically, it was predicted that higher levels of anxious attachment would increase the extent to which higher scores on the Stockholm scale would be associated with intimate partner violence.

This could be the case for two reasons. First, anxiously attached individuals may feel the need to control their partners and be less able to regulate their own levels of aggression, which would predict violence (Follingstad, Bradley, Helff, \& Laughlin, 2002). Second, when aggression is more prevalent in relationships, this is likely to produce higher levels of anxiety (Bookwala \& Zdaniuk, 1998). In contrast, lower levels of anxious attachment should buffer this association and reduce the connection between Stockholm syndrome and violence.

Regarding avoidant attachment, the second hypothesis was also based on previous research. One study (Babcock, Jacobson, Gottman, \& Yerington, 2000) found that males with avoidant attachment styles became violent primarily when their wives became defensive. Anxiously attached men were similar to a borderline personality profile and tended to use violence when their wives attempted to withdraw from them. Dutton (2006) found similar results. Doumas (2008) found that the pairing of an anxiously attached female with an avoidantly attached male was a particularly potent predictor of aggression. Interestingly, one study conducted in the Netherlands (Kuijpers, van der Knaap, \& Winkel, 2012) found that an elevated avoidant attachment style was a strong predictor of 
increased repeated victimization for females, particularly those with high and average anger levels.

However, these studies were based on male offenders in clinical samples who were experiencing marital distress or receiving court-ordered treatment for violence. These samples display higher levels of aggression than would be expected in community samples. Nonetheless, the direction of the relationship between the variables may be replicated in a community sample. Therefore, it was hypothesised that avoidant attachment would heighten the positive relationship between the Stockholm syndrome scales and reported aggression. In short, a higher degree of insecure attachment, whether anxious or avoidant, was expected to be associated with the extent to which higher scores on the Stockholm scale would be associated with more intimate partner violence.

Finally, three hypotheses were made regarding the data as a whole. First, I expected that relatively low levels of overall violence would be reported due to the community-based nature of the sample. Second, reflecting the standard results in this field and for a community sample, no gender differences in violence were predicted. Third, self-reported and partner-reported violence were expected to be strongly positively correlated.

To summarise, I predicted that higher scores on the Core component of the Stockholm syndrome scale would be moderately related to increased levels of self- and partner-violence. In contrast, I had no specific predictions for the Damage and Love components. Insecure attachment (whether anxious or avoidant) was expected to be associated with higher scores on the Stockholm scale. Finally, reports of violence were expected to be mild in severity, bi-directional, and gender symmetrical. 


\section{Method}

The data from Study 1 were reanalysed for Study 2 . The same materials, procedure, and exclusion criteria were used, but the additional analyses of attachment and aggression were included.

\section{Participants.}

The 508 participants described in Study 1 also provided the data, as part of the same online survey, for Study 2.

\section{Materials.}

Attachment scales. The three types of attachment (Secure, Anxious, Avoidant) in adult relationships were measured using the Adult Attachment Questionnaire (Simpson, Rholes, \& Nelligan, 1992). The reliability and validity of this measure has been established by a large body of previous research. Respondents replied on a 7-point Likert scale from 1 (Strongly disagree) to 7 (Strongly agree). Examples of secure, anxious, and avoidant items include "I find it relatively easy to get close to others," "I usually want more closeness and intimacy than others do," and "I'm somewhat uncomfortable being too close to others," respectively. Well-replicated research shows these three subscales (Secure, Anxious, Avoidant) effectively reduce to two dimensions: anxiety and avoidance (Becker, Billings, Eveleth, \& Gilbert, 1997; Huang \& Chen, 2011; Conradi, Gerlsma, Duijn, \& Jonge, 2006). Thus, using the standard approach, the mean score for secure attachment was subtracted from the mean score for the avoidant scale to produce one variable of avoidance. See Appendix B for a list of all scales and items used in this study.

Aggression measure. A modified version of the conflict tactics inventory (Straus, 1979) was used to measure aggression. This study used 10 items assessing both selfperpetrated violence $(\alpha=.52$ in this study) and partner-perpetrated violence $(\alpha=.63$ in 
this study). The terminology of the original scale was also altered to be gender neutral. Respondents were told not to include incidents that occurred in the context of "playing or joking." In each item, participants were asked, "How many times in the last year did the following happen?" Example items are: "I slapped my partner" and "My partner slapped me." Participants were then instructed to select responses from two drop down lists, one for self-violence and one for partner-violence. Responses fell on 6-point scales, and the options were: I never did this in the last year; This happened once in the last year; This happened twice in the last year; This happened 3 to 5 times in the last year; This happened 6-10 times in the last year; or This happened more than 20 times in the last year. For the partner-violence items, the pronouns were changed from "I" to "My partner" in the first option (i.e. My partner never did this in the last year). See Appendix B for a list of all scales and items used in this study.

\section{Results}

\section{Descriptive Results.}

The means and standard deviations for the Core, Damage, and Love components of the Stockholm syndrome scale can be seen in Study 1. Females reported lower mean scores of Core and Love than males but higher mean scores on the Damage component. No predictions were advanced concerning gender differences and thus will not be discussed further.

The measures of self-reported and partner-reported violence were very strongly correlated $(r=.75)$ and, for this reason, were summed to produce one variable, named relationship violence. The variable of relationship violence differs from the previously defined variable of intimate partner violence in that relationship violence is bidirectional while intimate partner violence is unidirectional. No significant gender differences were 
found in reports of relationship violence; for females, $M=1.12$, and for males, $M=1.11$. These low means indicate low levels of severe intimate partner violence in the general population. However, enough variance was present in the sample for meaningful analyses.

\section{Correlations and Multiple Regressions.}

As can be seen in Table 3, the correlations between the three Stockholm syndrome subscales and relationship violence showed a pattern of positive and significant associations ranging from .16 to .36 . It is also noteworthy that the three subscales for the Stockholm syndrome scale were moderately positively correlated (from $r=.38$ to $r=.40$; see Table 3). In order to disentangle the effect each of the Stockholm components had on relationship violence was simultaneously regressed on the three components of the Stockholm Syndrome Scale (see Table 3).

Table 3

Correlations and Beta Weights between Components of the Stockholm Syndrome Scale and Aggression

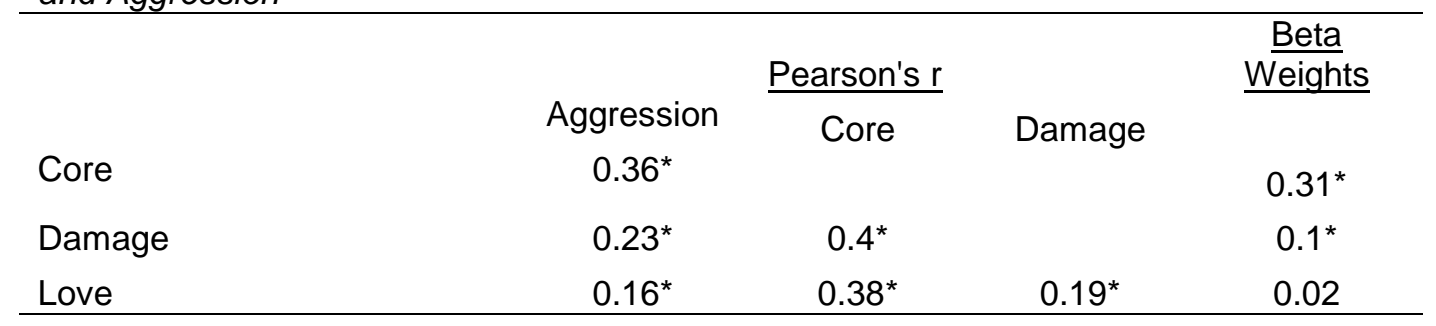

${ }^{*} p<0.1$

\section{Moderating Analyses.}

The dependent variable in this analysis was relationship violence, with self- and partner-reported violence combined. The independent variables were attachment style and Stockholm syndrome, with attachment style as the moderating variable. Six independent analyses were completed, with the three Stockholm syndrome scores (Core, Damage and Love) and the two moderating effects of avoidance and anxiety. Of the six possible 
moderating combinations, two were found to produce significant interactions: the interaction between Anxiety and Love Dependency $(t=0.22, p=.022)$ and the interaction between Avoidance and Core $(t=.011, p=.010)$.

Using the software produced by Paul Jose (2013), these two significant interactions were graphed. As can be seen in Figure 4, low levels of anxiety were associated with a weak link between Love Dependency and relationship violence, while high levels of anxiety heightened the same association. The second significant moderating analysis found that higher scores of avoidant attachment exacerbated the positive relationship between Core Stockholm syndrome and relationship violence, while lower scores of avoidant attachment ameliorated the same association (see Figure 5).

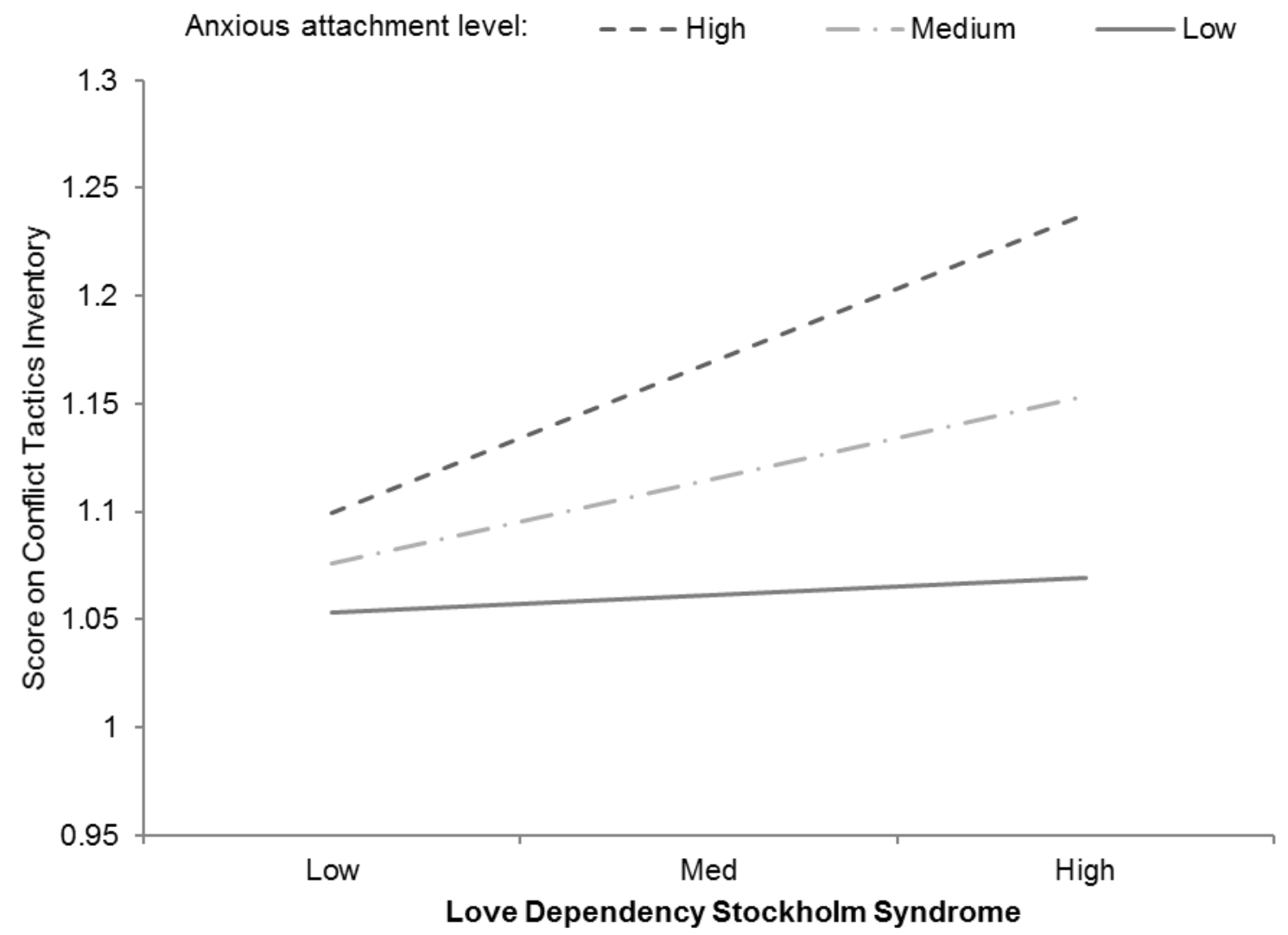

Figure 4. Love Dependency predicting level of intimate partner violence as moderated by the degree of anxious attachment. 


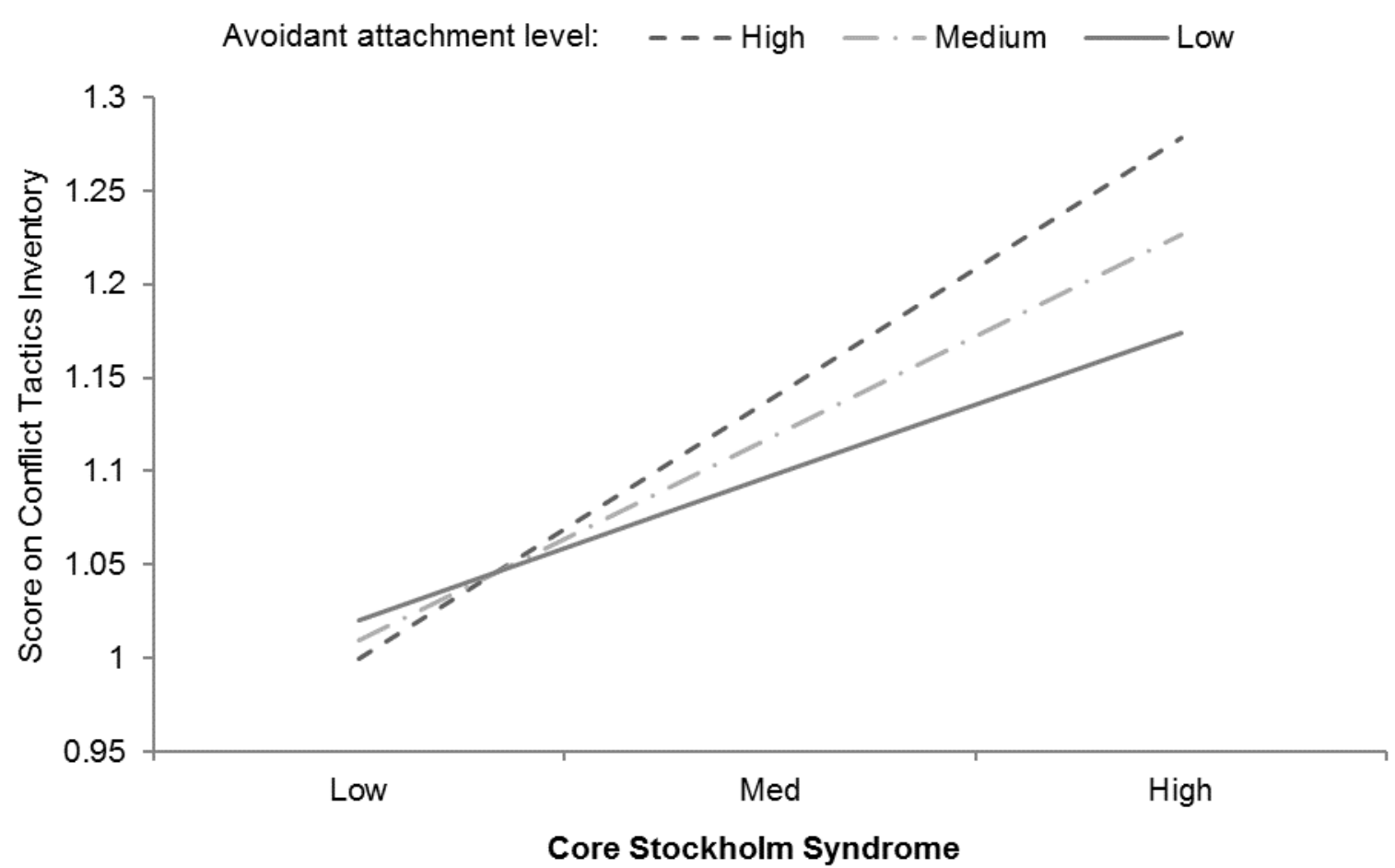

Figure 5. Core Stockholm syndrome predicting intimate partner violence as moderated by level of avoidant attachment.

\section{Discussion}

As expected, low levels of gender symmetrical and bi-directional violence were reported, as is typical in general community samples. The main effects showed that higher scores of relationship violence were linked to higher levels of the three components of the Stockholm syndrome scale (Core, Damage, and Love). As anxiety increased, the link between Love and relationship violence also increased. Participants high in anxious attachment and Love dependency were more vulnerable to relationship violence, whereas those low in anxious attachment were not as vulnerable.

As previously noted, this finding is plausible. People who are anxiously attached are likely to be more preoccupied with their relationships. Given that they also view their partners as critical to their central identity and survival (love dependency), the abuse is likely to be justified in their minds. Those who believe they have nothing to live for 
without their partners and who constantly seek reassurance because they doubt their relationships may help produce more aggressive responses in their partners, who may tire of constantly reassuring and soothing them. Conversely, high levels of insecurity, frustration, and excessive monitoring may trigger displays of aggression.

The second significant interaction showed that higher levels of avoidant attachment were associated with a stronger positive link between Core and relationship violence. It could be that adopting a distant and disengaged presence may anger one's partner, who then becomes abusive in an effort to force his or her avoidant partner to interact. In this event, the avoidant individual may justify the abuse, blame him- or herself, and see his or her partner as a victim rather than an abuser. These cognitions are in fact the foundation of the Core construct. Alternately, high levels of avoidance may motivate the initiation of relationship violence, which then feeds back to produce higher levels of justification.

\section{Study 3}

In Study 3, dyadic data was analysed from couples residing in New Zealand. This study was partly exploratory but also served to test and replicate some of the prior findings. Structural Equation Modelling (SEM) was used in order to investigate the associations between Stockholm syndrome components and reported aggression. An interdependence framework, the standard method of choice with dyadic data, was utilized. The main predictions were that the three Stockholm syndrome components (Core, Damage, and Love) would show associations with reported aggression. Partner effects were also examined on an exploratory basis. 
Other hypotheses focused on replicating the findings reported in the prior two studies and previous research. First, the Core component of the Stockholm syndrome scale was predicted to have the strongest association with reported aggression, while the Damage and Love components were expected to have weaker associations (as in study 2). Second, higher relationship quality was expected to be associated with lower intimate aggression and lower levels of the Stockholm syndrome factors. Third, I predicted that low levels of overall violence would be reported, no significant gender differences in reported violence would be found, self-reported and partner-reported violence would be very strongly correlated, and the three Stockholm syndrome components would show a pattern of positive and significant associations with one another.

\section{Method}

\section{Participants.}

Eighty-six couples $(N=172,86$ male and 86 female participants), ranging in age from 19 to 56 years of age $(M=28.4$ years, $S D=8.2$ years $)$ and residing in New Zealand, contributed to this study. All participants identified as being in a committed relationship with the majority (54.7\%) indicating their relationship status as "Living together," $26.7 \%$ as "Married," and 18.6\% as "Dating." The duration of relationships ranged from eight months to 24 years $(M=4.8$ years, $S D=5.4$ years $)$.

\section{Exclusion Criteria.}

A small number of participants $(n=20)$ were excluded due one or more of the following criteria: a) only one partner filled out the survey, b) the survey was not filled out completely, c) the couple identified as being in a same-sex relationship (creating difficulties in data analysis), d) one or both respondents were under 18 years of age, or e) respondents did not respond to emails. 


\section{Materials.}

Modified versions of four scales were used in an online survey (see Appendix B for a list of all scales and items used in this study). All scales implemented in this study have shown excellent reliability and validity in prior research (Fletcher, Simpson, \& Thomas, 2000; George, 2013; Simpson et al., 1992; Straus, 1979). Total scores were calculated for all scales and subscales used in this study.

Stockholm syndrome scale. Refer to Study 1 and Study 2 for an overview of the Stockholm syndrome scale.

Aggression measure. The Conflict Tactics Inventory was utilized to measure aggression in this study $(\alpha=.74)$. See study 2 for a description of the Conflict Tactics Inventory.

Perceived Relationship Quality Scale. A short version of the Perceived Relationship Quality Scale was used in this study. This measure consists of six items $(\alpha=$ .76 in this study). An example item from this scale is: "How satisfied are you with your relationship?" Responses were made on a 7-point Likert scale, ranging from 1 (Not at all) to 7 (Extremely). Participants were also asked how they thought their partners would rate their relationships ( $\alpha=.80$ in this study). An example item is: "How satisfied is your partner with your relationship?"

\section{Procedure.}

The current study formed part of a larger, longitudinal study. Participants were recruited to participate in this study via an email sent by Victoria University of Wellington to all psychology students attending the university. Participants were also recruited from social media groups such as Facebook and Reddit with New Zealand memberships. Participants were rewarded with a \$15 NZ supermarket voucher on 
completion of the survey and given the opportunity to participate again six months later for the same reward. Ethical approval was sought and granted from the Human Ethics Committee of Victoria University of Wellington.

\section{Results}

\section{Descriptive Analyses.}

The means and standard deviations for each component (Core, Damage, and Love) of the Stockholm syndrome scale and reported aggression levels are shown in Table 4. As is typical in such samples, the scores on the scales were positively skewed. Note, however, that scores on the Stockholm syndrome components are relatively high when compared to relationship violence scores.

\section{Correlations.}

The correlations among the three measures (Stockholm syndrome scale, relationship quality, and CTI) are shown in Table 5. Higher relationship quality was associated most strongly with lower scores on Core, while the correlations with Damage and Love were weak. The three subscales for the Stockholm Scale were also moderately positively correlated (from .27 to .39; see Table 5). The construct of Damage did not correlate with reported aggression or either of the other two Stockholm syndrome constructs. Finally, male- and female-reported intimate aggression was strongly correlated across partners, showing high levels of agreement.

Table 4.

Means and Standard Deviations of the Three Components of the Stockholm Syndrome Scale and Reported Aggression (Study 3)

\begin{tabular}{|c|c|c|c|c|c|c|}
\hline $\begin{array}{l}\text { Stockholm } \\
\text { Syndrome } \\
\text { Component }\end{array}$ & $\begin{array}{c}\text { Females }+ \\
\text { Mean }\end{array}$ & $\begin{array}{c}\text { Std. } \\
\text { Deviation }\end{array}$ & PRange & $\begin{array}{l}\text { Males } \hat{\imath} \\
\text { Mean }\end{array}$ & $\begin{array}{c}\text { Std. } \\
\text { Deviation }\end{array}$ & d'Range \\
\hline Core & 1.67 & 0.96 & 4.63 & 1.94 & 1.01 & 3.63 \\
\hline Damage & 3.49 & 0.67 & 2.88 & 3.28 & 0.61 & 2.63 \\
\hline Love & 2.77 & 1.15 & 4.88 & 2.77 & 1.04 & 4.25 \\
\hline Aggression & 2.25 & 0.37 & 2.11 & 2.26 & 0.46 & 2.33 \\
\hline
\end{tabular}


Table 5

Within-Gender and Between-Partner Correlations for the Three Components of the Stockholm Syndrome Scale and Reported Aggression (Study 3).

\begin{tabular}{|c|c|c|c|c|c|c|c|c|c|}
\hline & $\underline{\lambda}$ Core & ¿Damage & ¿'Love & $\underline{\text { Aggression }}$ & $\begin{array}{l}\text { QRelationship } \\
\text { Satisfaction }\end{array}$ & 오으 & 오amage & 으ove & 오gression \\
\hline $\begin{array}{l}\text { TRelationship } \\
\text { Satisfaction }\end{array}$ & $-.34^{\star \star}$ & $-.21^{*}$ & .13 & -.12 & $.49^{\star \star}$ & $-.22^{*}$ & -.08 & .04 & .08 \\
\hline Core & & $.39^{* *}$ & $.29^{\star \star}$ & $.50^{\star *}$ & -.06 & $.33^{\star *}$ & -.12 & $.23^{*}$ & $.30^{* *}$ \\
\hline ¿Damage & & & $.27^{* *}$ & .12 & .06 & .19 & -.12 & $.26^{*}$ & .13 \\
\hline ð’Love & & & & .07 & .09 & .18 & -.01 & $.23^{\star}$ & .13 \\
\hline${ }^{\lambda}$ Aggression & & & & & -.13 & $.34^{* *}$ & .02 & $.36^{* *}$ & $.68^{\star \star}$ \\
\hline $\begin{array}{l}\text { PRelationship } \\
\text { Satisfaction }\end{array}$ & & & & & & $-31^{* *}$ & -.16 & -.02 & .04 \\
\hline qCore & & & & & & & .15 & $.44^{* *}$ & $.37^{* *}$ \\
\hline qDamage & & & & & & & & .18 & .03 \\
\hline qLove & & & & & & & & & $.36^{\star *}$ \\
\hline
\end{tabular}

Notes. ${ }^{*} p<.05,{ }^{* *} p<.01 \ldots \ldots \ldots \ldots \ldots \ldots \ldots$ Across-partner results are in boldface. 


\section{Associations between Stockholm syndrome components and reported}

aggression. Structural equation modelling (SEM) was used to further examine the associations between the three components of the Stockholm syndrome scale (Core, Damage, and Love) and reported aggression. A SEM approach allowed within-participant effects as well as partner effects to be tested while controlling for shared variance between the male and female partners.

In light of the high correlation between the two variables $(r(85)=.68, \mathrm{p}<.01$; see Table 7), self- and partner-reported intimate partner violence were combined into one variable to produce a measure of relationship violence. In each analysis, gender differences between paths were tested by setting the equivalent paths across each gender as equal and comparing the chi-square measuring fit to the model in which all the paths were independent. In the cases of Core $\left(\chi^{2}(2)=2.34, p>.05\right)$ and Damage $\left(\chi^{2}(2)=0.9, p\right.$ $>$.05), no significant gender differences were found and the paths were set to equality at the unstandardized level (which increases the power of the analysis). Hence, the standardized pool paths (shown in Figures 6-8) may differ across gender. In the case of the Love component, significant gender effects were found $\left(\chi^{2}(2)=7.55, p<.05\right)$ so the paths were not pooled.

In all three of the SEM analyses that follow, relationship satisfaction was also controlled for. However, in all three analyses, controlling for relationship quality had no effect on the relationship between the Stockholm syndrome component tested and reported aggression.

Associations between Core and reported aggression. In the first analysis (see Figure 6), the Stockholm syndrome construct of Core was the independent variable and reported aggression was posited as the dependent variable. The results showed that both 
males and females who possessed higher levels the cognitive distortions and justifications associated with the Core construct reported more aggression in their relationships.

Moreover, two significant partner effects were found, showing that higher levels of Core for both men and women were associated with higher levels of relationship violence reported by their partners.

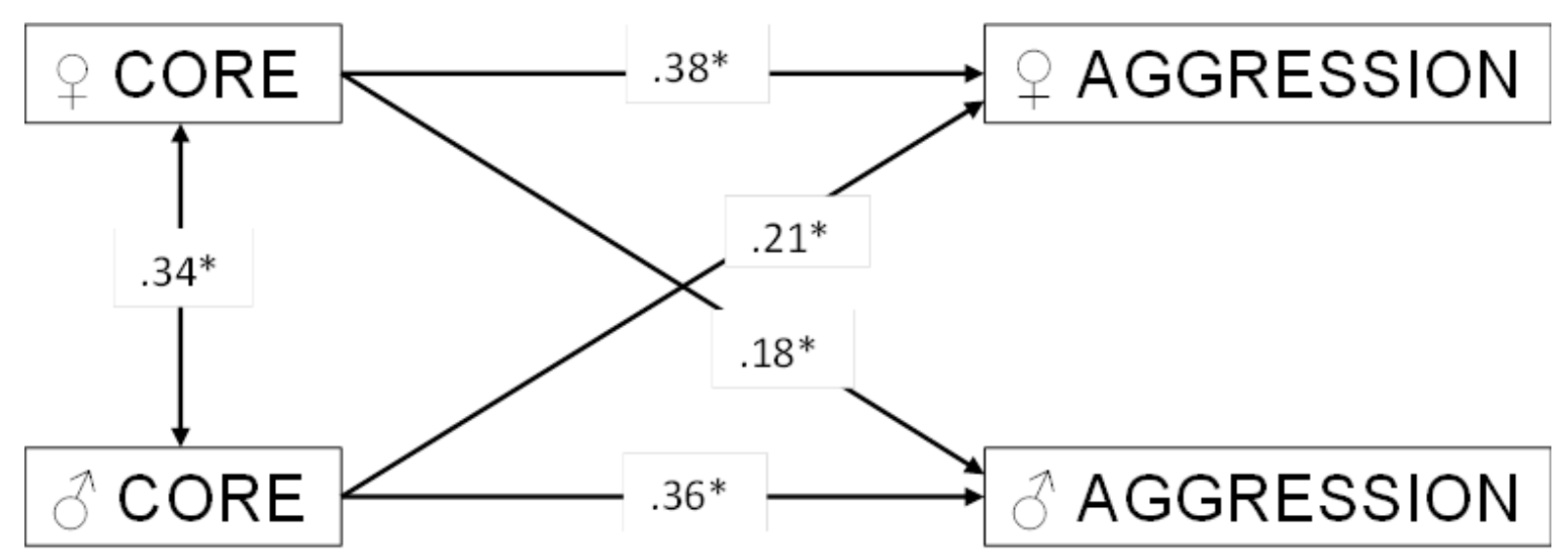

Note. ${ }^{*} p<.05$

Figure 6. Associations between Core and Reported Aggression.

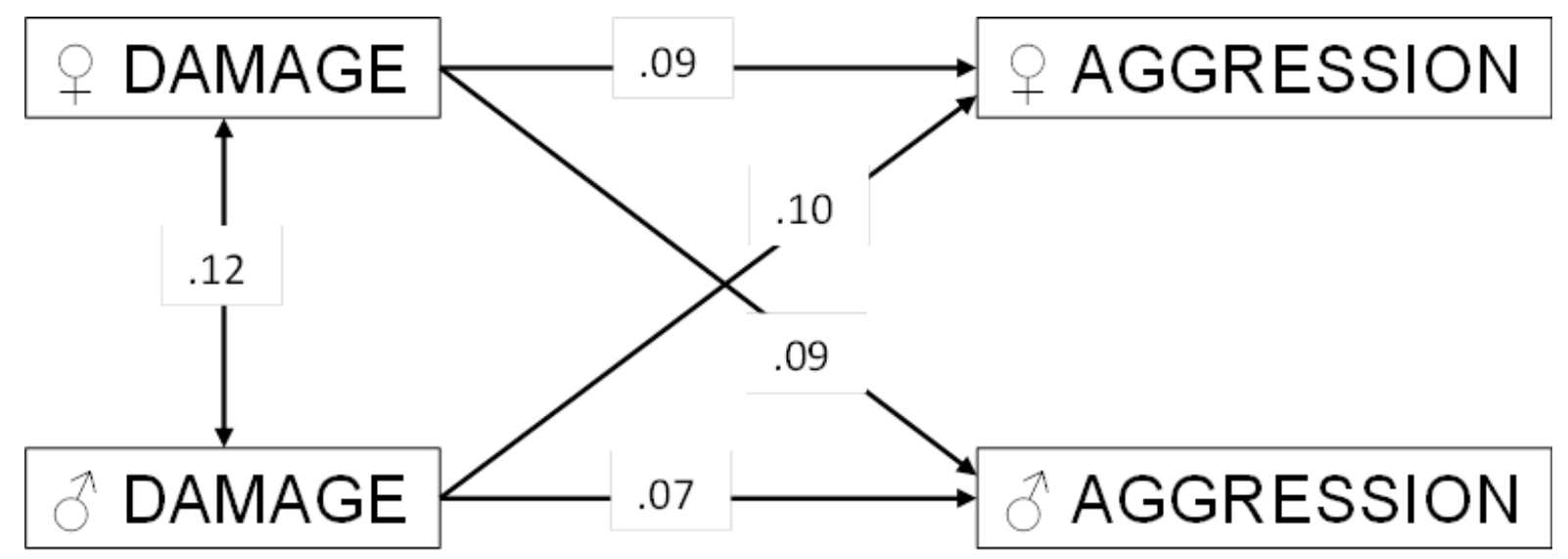

Note. ${ }^{*} p<.05$

Figure 7. Associations between Damage and Reported Aggression. 
Associations between Damage and reported aggression. The second analysis

(see Figure 7) examined the link between the constructs of Damage and reported aggression in the relationship. No significant effects were found.

Associations between Love and reported aggression. The third analysis (see

Figure 8) explored the possible link between the construct of Love and reported aggression. In this case, significant gender differences were found between paths; therefore, the paths were not set to equality. More female Love was associated not only with increased female aggression but also with higher male aggression. However, male Love was not associated with neither female nor male reported aggression.

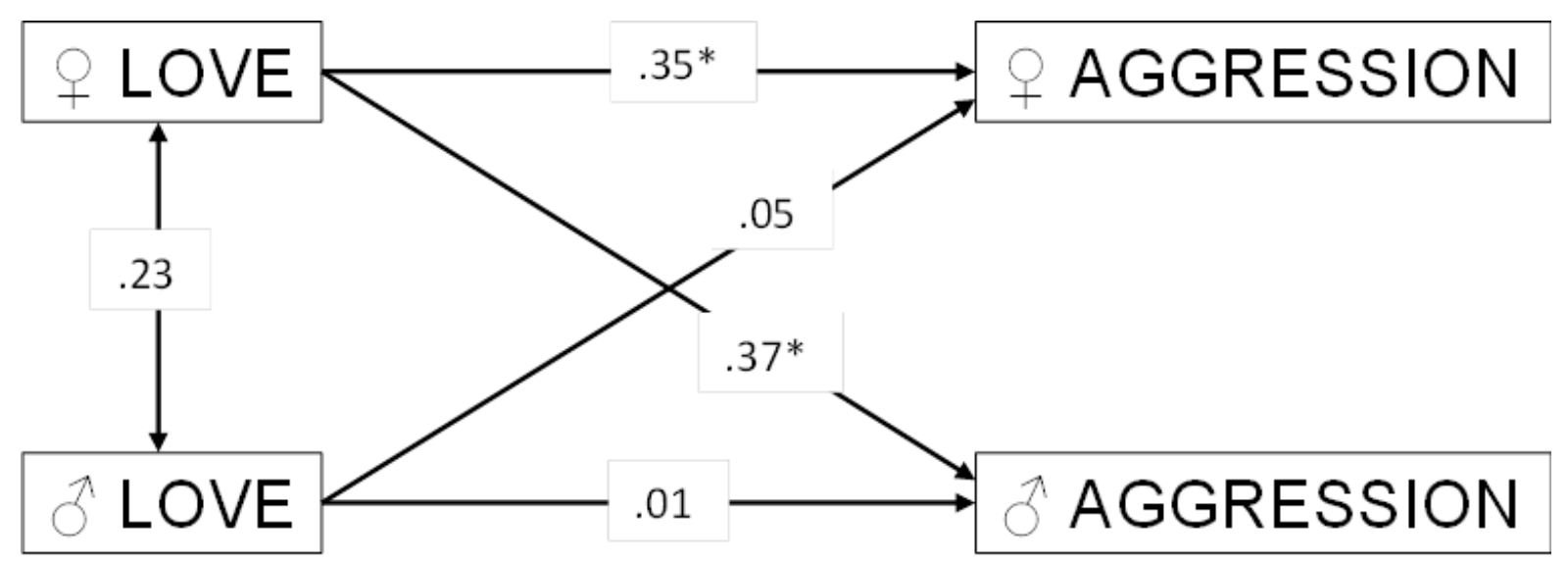

Note. ${ }^{*} p<.05$

Figure 8. Associations between Love and Reported Aggression. 


\section{Discussion}

The findings of this study are of great interest. For the first time, dyadic data from the Stockholm syndrome scale was analysed across couples. Both primary and secondary hypotheses were at least partially supported.

\section{Stockholm Syndrome and Relationship Violence.}

The main hypothesis, that the Core construct would be associated with more relationship violence, was confirmed. Moreover, two clear partner effects were found, showing that higher levels of Core for both men and women were associated with higher levels of relationship violence reported by their partners. These findings also remained robust when relationship quality was controlled, which suggests this variable is not a third factor driving the link between Core and relationship violence. This finding was expected, as previous research has shown that the Core construct is the principal factor associated with relationship violence. These results suggest that Core has dyadic influences, beyond intra-individual processes, although the data are correlational.

Some unexpected findings did arise. No associations were found between the Damage construct and relationship violence, and, in the case of the Love construct, significant associations were found only between female scores of Love and relationship violence. Interestingly, more female Love was associated not only with increased female relationship violence but also with higher male relationship violence. This may be because women monitor relationships more than men (Fletcher et al., 2013), are more sensitive to interpersonal issues and problems (Tannen, 1991), and tend to ruminate in more complex ways (Calmes \& Roberts, 2008). Males tend to distract themselves rather than ruminate about a relationship (Nolen-Hoeksema, 1987). 


\section{Relationship Quality.}

Regarding relationship quality, a very similar pattern across genders was found, showing that, although Core is quite strongly related to relationship satisfaction for both men and women, Damage and Love are weakly linked to relationship satisfaction. This finding supports the notion that Core cognitions are a fundamental part of human social cognition and thus are important for both genders.

\section{Secondary Hypotheses.}

Other secondary hypotheses were also supported. Specifically, low levels of overall violence were reported, as is typical of community samples, and there were no significant gender differences in reported violence. In addition, self-reported and partnerreported violence were strongly correlated. Finally, the three Stockholm syndrome components showed a pattern of positive and significant associations.

\section{General Discussion}

The current study adapted the Stockholm syndrome scale for use in studying intimate aggression and tested its validity. The scale is intended to measure cognitive distortions and justifications relating to intimate aggression. Three studies were conducted. The first study tested the psychometric qualities of the scale, the second assessed the predictive validity of the scale, and the third study analysed dyadic data from couples. In general, the results of this research were consistent with predictions and provided substantial support for the internal and external validity of the Stockholm syndrome scale, whilst providing some novel findings.

Study 1 showed that the scale had strong internal reliability. The confirmatory factor analysis indicated that a three-factor model fit the data considerably better than a single-factor model. The study also found that Stockholm syndrome cognitions are quite 
prevalent even in a general population sample. Study 2 found, as expected, a main effect such that higher scores of relationship violence were associated with higher levels of all three components of the Stockholm syndrome scale. However, this relationship may be moderated by insecure attachment. Specifically, avoidant attachment strengthened the positive relationship between the Core component and relationship violence. Similarly, anxious attachment strengthened the correlation between the Love component and relationship violence. The significance of these findings is of substance, as they offer a new perspective on which personal factors contribute to intimate aggression in adult relationships.

Using a dyadic data set, Study 3 confirmed that higher levels of Core were associated with greater relationship violence within the individual. However, two clear partner effects were also found. First, higher levels of Core for both men and woman were associated with more relationship violence reported by their partners, even after controlling for relationship quality. Second, more Love (for females only) was associated with more male relationship violence. These findings suggest that Stockholm syndrome constructs have dyadic influences over and above intra-individual processes.

Regarding the first partner effect, it could be that Core is more fundamental than the other factors. Justifying behaviour, excusing it and rationalizing it, may be such a fundamental part of human cognition that it is seen in both men and women. In contrast, Love seems to be a more nuanced, subtle, and sophisticated notion. Perhaps for that reason, Love is only linked to relationship violence in women, who tend to be more subtle and sophisticated and ruminate in more complex ways (Fletcher et al., 2013).

Gender differences in intimate relationships are well-documented and may help explain the Love partner effect in part. In intimate relationships, women tend to monitor 
and think more extensively about relationships than men and are more intensely focused on the level of investment in the relationship (Fletcher et al., 2013). This may be due to societal pressures and mores, which dictate that a woman must be partnered and negatively view single women (i.e. the "old maid" stereotype as opposed to the "swinging bachelor"). Alternatively, violent men may attract violent women (Robertson \& Murachver, 2007).

These interpretations are speculative. However, it is clear that levels of dyadic aggression for both men and women are associated with how the woman perceives the relationship in terms of Love cognitions. Future research should explore this association further.

\section{Study Strengths}

The results of this research both support and extend previous work in the area of traumatic bonding and relationship violence. The population from which the participants for studies 1 and 2 were drawn was large, diverse, and international, which expands considerably on populations previously used. The analysis of dyadic data from couples in study 3 provided the first analysis of this kind and proffers a first step in delving into the inter-partner effects of the Core construct, as well as documenting the novel finding that female scores of Love have associations with relationship violence. Finally, it is well documented that general community samples display low overall levels of asymmetrical relationship violence (e.g. male as perpetrator and woman as victim) and also less severe relationship violence overall. The fact that the populations studied behaved in the same predictable ways lends further validity to the novel findings. 


\section{Caveats and Future Directions}

The current research adds significant data to the existing literature on intimate aggression, but there are limitations which need to be addressed by future research.

Love, gender and violence. The role of the Love component, specifically why it differs between sexes and why only female scores of Love are associated with relationship violence, is not clear. This novel finding, however, may provide the impetus for further research including a clinical sample and using an Intimate Terrorism scale (Johnson, 2008) or the Dark Triad scale (Paulhus \& Williams, 2002). It is possible that hyper-masculine or dark-personality males (those high in narcissism, Machiavellianism and psychopathy) are triggered by violent and aggressive females because such females threaten the dominant role hyper-masculine males expect to have in their relationships. Alternatively, pugnacious females may be attracted to violent males. Future research is necessary to investigate the causes of this particular finding.

Sampling. A second limitation is the nature of the samples. While the samples included both males and females from diverse backgrounds and countries of residence in study 1 and 2 and dyadic data from New Zealand couples in study 3, the participants involved were all drawn from so-called WEIRD (Western, Educated, Industrialized, Rich, and Democratic) populations (Henrich, Heine, \& Norenzayan, 2010). Furthermore, while participants in self-defined same-sex relationships were included in studies 1 and 2, it was not possible to analyse data from same-sex couples in study 3.

Broad claims about human psychology and behaviour could be tenuous based on such samples. For example, it is possible that members of other cultures would not fit a 3factor scale for Stockholm syndrome. Moreover, the Stockholm scale may yield different 
results within a clinical population. A population that included repeat and chronic victims and perpetrators of intimate partner violence would be of particular interest.

Recall that repeat and chronic victims of intimate partner violence experience $88 \%$ of all intimate partner violence, despite representing only $3 \%$ of all victims (New Zealand Ministry of Justice, 2010). If future research confirms the applicability of this scale to such a population, it could be useful as a diagnostic tool. Furthermore, programmes serving people in violent relationships might effectively incorporate cognitive behavioural therapy that specifically addresses Stockholm syndrome cognitions.

Longitudinal potential. Another limitation is that, although collected from the participants in study 3, longitudinal data were not included in the analysis for this study due to time and scope constraints. It would be useful to examine these data, in particular the consequences of high Love scores for women. Longitudinal research may enable researchers to determine the extent to which high Love scores for women are a response to versus a cause of relationship violence.

Terminology. Finally, the term "Stockholm syndrome" may not be the most appropriate in this context. Certainly, it is clear that a traumatic form of bonding and identifying with a "captor" are major components of severe intimate aggression.

However, the term "Stockholm syndrome" implies that the roles of captor and hostage are clearly defined and not interchangeable, whereas the results of this study suggest that these roles are not so clearly defined.

\section{Conclusion}

Intimate aggression is a pervasive and detrimental phenomenon throughout society. It affects men and women and results in a variety of negative psychological, physical, and social problems. As indicated by the current study, however, the cause of 
such violence is complex, and preventing it will require an equally complex solution. The interaction between attachment style, Stockholm syndrome, and intimate aggression illustrates some facets of this reality and may provide the impetus for a large body of future research. The current study has added to the very small body of literature pertaining to traumatic bonding and relationship violence, a much understudied area that has remained largely dormant in the $21^{\text {st }}$ century. However, substantial additional research will be required if the sources of intimate aggression are to be fully understood and effectively addressed.

\footnotetext{
"And the victim must have been broken and must remain so, so that the externalization of evil is possible. The victim who refuses to assume this role contradicts society's simplistic view. Nobody wants to see it. People would have to take a look at themselves."

- Natascha Kampusch, 3096 days
} 
References

Abel, E. (2001). Comparing the social service utilization, exposure to violence, and trauma symptomology of domestic violence female "victims" and female “batterers.” Journal of Family Violence, 16, 401-420. doi:10.1023/A:1012276927091

Ainsworth, M. D. (1979). Infant-mother attachment. The American Psychologist, 34, 932-937. doi:10.1037/0003-066X.34.10.932

Ainsworth, M. D., \& Bell, S. M. (1970). Attachment, exploration, and separation: Illustrated by the behavior of one-year-olds in a strange situation. Child Development, 41, 49-67. doi:10.2307/1127388

Archer, J. (2002). Sex differences in physically aggressive acts between heterosexual partners: A meta-analytic review. Aggression and Violent Behavior, 7, 313-351. doi:10.1016/S1359-1789(01)00061-1

Arias, I., \& Johnson, P. (1989). Evaluations of physical aggression among intimate dyads. Journal of Interpersonal Violence, 4, 298-307. doi:10.1177/088626089004003004

Arriaga, X. B., \& Foshee, V. A. (2004). Adolescent dating violence: Do adolescents follow in their friends', or their parents', footsteps? Journal of Interpersonal Violence, 19, 162-184. doi:10.1177/0886260503260247

Becker, T. E., Billings, R. S., Eveleth, D. M., \& Gilbert, N. W. (1997). Validity of scores on three attachment style scales: Exploratory and confirmatory evidence. Educational and Psychological Measurement, 57, 477-493. doi:10.1177/0013164497057003009 
Beckes, L., \& Coan, J. A. (2013). Voodoo versus me-you correlations in relationship neuroscience. Journal of Social and Personal Relationships, 30, 189-197. doi:10.1177/0265407512454768

Bejerot, N. (1974, February 21). The six day war in Stockholm. New Scientist, 61, 486487.

Bentler, P. M. (1995). EQS structural equations program manual. Los Angeles, CA: Multivariate Software, Inc.

Berant, E., Mikulincer, M., Shaver, P. R., \& Segal, Y. (2005). Rorschach correlates of self-reported attachment dimensions: Dynamic manifestations of hyperactivating and deactivating strategies. Journal of Personality Assessment, 84, 70-81.

Berns, N. (2004). Framing the victim: Domestic violence, media, and social problems. Hawthorne, NY: Aldine de Gruyter.

Billingham, R. E., \& Sack, A. R. (1986). Courtship violence and the interactive status of the relationship. Journal of Adolescent Research, 1, 315-325. doi: $10.1177 / 074355488613006$

Bowlby, J. (1977). The making and breaking of affectional bonds. I. Aetiology and psychopathology in the light of attachment theory. An expanded version of the Fiftieth Maudsley Lecture, delivered before the Royal College of Psychiatrists, 19 November 1976. The British Journal of Psychiatry, 130, 201-210. doi:10.1192/bjp.130.3.201

Bretherton, I. (1992). The origins of attachment theory: John Bowlby and Mary Ainsworth. Developmental Psychology, 28, 759-775. doi:10.1037/00121649.28.5.759 
Brinkerhoff, M. B., \& Lupri, E. (1988). Interspousal violence. Canadian Journal of Sociology/Cahiers Canadiens de Sociologie, 13, 407-434.

Calmes, C., \& Roberts, J. (2008). Rumination in interpersonal relationships: Does corumination explain gender differences in emotional distress and relationship satisfaction among college students? Cognitive Therapy and Research, 32, 577590. doi:10.1007/s10608-008-9200-3

Campbell, L., Simpson, J. A., Boldry, J., \& Kashy, D. A. (2005). Perceptions of conflict and support in romantic relationships: The role of attachment anxiety. Journal of Personality and Social Psychology, 88, 510-531. doi:10.1037/0022-3514.88.3.510

Demarest, R. A. (2009). The relationship between Stockholm syndrome and posttraumatic stress disorder in battered women. Student Pulse, 1(11), 1-3. Retrieved from http://www.studentpulse.com

Dutton, D. G., \& Painter, S. (1993). Emotional attachments in abusive relationships: A test of traumatic bonding theory. Violence and Victims, 8, 105-120.

Dutton, D. G., \& White, K. R. (2012). Attachment insecurity and intimate partner violence. Aggression and Violent Behavior, 17, 475-481. doi:10.1016/j.avb.2012.07.003

Ehrensaft, M. K., Moffitt, T. E., \& Caspi, A. (2004). Clinically abusive relationships in an unselected birth cohort: Men's and women's participation and developmental antecedents. Journal of Abnormal Psychology, 113, 258-270. doi:10.1037/0021843X.113.2.258

Festinger, L. (1957). A theory of cognitive dissonance. Stanford, CA: Stanford University Press. 
Festinger, L. (1962, October 1). Cognitive dissonance. Scientific American, 207(4), 93106. doi:10.1038/scientificamerican1062-93

Finley, R. (1999). Survey monkey [computer software]. Available from WwW.surveymonkey.com

Fletcher, G. J. O., Simpson, J. A., \& Thomas, G. (2000). The measurement of perceived relationship quality components: A confirmatory factor analytic approach. Personality and Social Psychology Bulletin, 26, 340-354. doi:10.1177/0146167200265007

Fletcher, G. J., Simpson, J., Campbell, L., \& Overall, N. (2013). The science of intimate relationships. Malden, MA: Wiley-Blackwell.

Frei, J. R., \& Shaver, P. R. (2002). Respect in close relationships: Prototype definition, self-report assessment, and initial correlates. Personal Relationships, 9, 121-139. doi:10.1111/1475-6811.00008

Frye, N. E., \& Karney, B. R. (2006). The context of aggressive behavior in marriage: A longitudinal study of newlyweds. Journal of Family Psychology, 20, 12-20. doi:10.1037/0893-3200.20.1.12

Galesic, M., \& Bosnjak, M. (2009). Effects of questionnaire length on participation and indicators of response quality in a web survey. Public Opinion Quarterly, 73, 349360. doi:10.1093/poq/nfp031

George, V. (2013). Stockholm syndrome and intimate partner violence (Unpublished honours thesis). Victoria University of Wellington, Wellington.

Graham, D. L. (1994). Loving to survive: Sexual terror, men's violence, and women's lives. New York, NY: New York University Press. 
Graham, D. L. R., Rawlings, E. I., Ihms, K., Latimer, D., Foliano, J., Thompson, A.,...Hacker, R. (1995). A scale for identifying "Stockholm syndrome" reactions in young dating women: Factor structure, reliability, and validity. Violence and Victims, 10, 3-22.

Graham-Kevan, N., \& Archer, J. (2003). Intimate terrorism and common couple violence: A test of Johnson's predictions in four British samples. Journal of Interpersonal Violence, 18, 1247-1270. doi:10.1177/0886260503256656

Gryl, F. E., Stith, S. M., \& Bird, G. W. (1991). Close dating relationships among college students: Differences by use of violence and by gender. Journal of Social and Personal Relationships, 8, 243-264. doi:10.1177/0265407591082005

Harlow, H. F., \& Suomi, S. J. (1970). Induced psychopathology in monkeys. Engineering and Science, 33(6), 8-14. Retrieved from http://calteches.library.caltech.edu/

Harmon-Jones, E., Brehm, J. W., Greenberg, J., Simon, L., \& Nelson, D. E. (1996). Evidence that the production of aversive consequences is not necessary to create cognitive dissonance. Journal of Personality and Social Psychology, 70, 5-16. doi:10.1037/0022-3514.70.1.5

Hazan, C., \& Shaver, P. (1987). Romantic love conceptualized as an attachment process. Journal of Personality and Social Psychology, 52, 511-524. doi:10.1037/00223514.52.3.511

Henrich, J., Heine, S. J., \& Norenzayan, A. (2010). The weirdest people in the world? Behavioral and Brain Sciences, 33, 61-83. doi:10.1017/S0140525X0999152X

Huang, Y., \& Chen, S. (2011). Psychometric properties of the Chinese version of revised adult attachment scale and its prediction to psychological adjustment. Chinese Journal of Psychology, 53, 209-227. doi:10.6129 / CJP 
Jan Conradi, H., Gerlsma, C., Duijn, M. van, \& Jonge, P. de. (2006). Internal and external validity of the experiences in close relationships questionnaire in an American and two Dutch samples. The European Journal of Psychiatry, 20, 258-269. doi:10.4321/S0213-61632006000400006

Johnson, M. P. (2008). A typology of domestic violence: Intimate terrorism, violent resistance, and situational couple violence. Boston, MA: University Press of New England.

Johnson, M. P., \& Ferraro, K. J. (2000). Research on domestic violence in the 1990s: Making distinctions. Journal of Marriage and the Family, 62, 948-963. doi:10.1111/j.1741-3737.2000.00948.x

Johnson, M. P., \& Leone, J. M. (2005). The differential effects of intimate terrorism and situational couple violence: Findings from the National Violence Against Women Survey. Journal of Family Issues, 26, 322-349. doi:10.1177/0192513X04270345

Jose, P. (2013). ModGraph-I: A programme to compute cell means for the graphical display of moderational analyses: The internet version (Version 3.0) [Software]. Available from http://pavlov.psyc.vuw.ac.nz/paul-jose/modgraph/

Lee, A., \& Hankin, B. L. (2009). Insecure attachment, dysfunctional attitudes, and low self-esteem predicting prospective symptoms of depression and anxiety during adolescence. Journal of Clinical Child \& Adolescent Psychology, 38, 219-231. doi:10.1080/15374410802698396

Letherby, G. (Ed.). (2008). Sex as Crime? Portland, OR: Willan.

Marsh, H. W., Balla, J. R., \& McDonald, R. P. (1988). Goodness-of-fit indexes in confirmatory factor analysis: The effect of sample size. Psychological Bulletin, 103, 391-410. doi:10.1037/0033-2909.103.3.391 
Mikulincer, M. (2007). Attachment in adulthood: Structure, dynamics, and change. New York, NY: Guilford Press.

Mikulincer, M., \& Shaver, P. R. (2007). Attachment in adulthood: Structure, dynamics, and change. New York, NY: Guilford Press.

Mills, L. G. (2008). Violent partners a breakthrough plan for ending the cycle of abuse. New York, NY: Basic Books.

New Zealand Ministry of Justice. (2010). The New Zealand crime and safety survey, 2009: Main findings report. Retrieved from http://www.justice.govt.nz/publications/global-publications/n/nzcass2009/documents/The\%20New\%20Zealand\%20Crime\%20and\%20Safety\%20Surv ey\%202009\%20Main\%20Findings\%20Rep.pdf/at_download/file

Nolen-Hoeksema, S. (1987). Sex differences in unipolar depression: Evidence and theory. Psychological Bulletin, 101, 259-282. doi:10.1037/0033-2909.101.2.259

Paulhus, D. L., \& Williams, K. M. (2002). The dark triad of personality: Narcissism, machiavellianism, and psychopathy. Journal of Research in Personality, 36, 556563. doi:10.1016/S0092-6566(02)00505-6

Ramsay, J. (2002). Should health professionals screen women for domestic violence? Systematic review. BMJ, 325, 314. doi:10.1136/bmj.325.7359.314

Reid, J. A., Haskell, R. A., Dillahunt-Aspillaga, C., \& Thor, J. A. (2013). Contemporary review of empirical and clinical studies of trauma bonding in violent or exploitative relationships. International Journal of Psychology Research, 8, 3773. 
Robertson, K., \& Murachver, T. (2007). It takes two to tangle: Gender symmetry in intimate partner violence. Basic and Applied Social Psychology, 29, 109-118. doi:10.1080/01973530701331247

Simpson, J. A., Rholes, W. S., \& Nelligan, J. S. (1992). Support seeking and support giving within couples in an anxiety-provoking situation: The role of attachment styles. Journal of Personality and Social Psychology, 62, 434-446. doi:10.1037/0022-3514.62.3.434

Snively, S. (1995). The New Zealand economic cost of family violence. Social Policy Journal of New Zealand, 4. Retrieved from https://www.msd.govt.nz/about-msdand-our-work/publications-resources/journals-and-magazines/social-policyjournal/index.html

Statistics New Zealand. (2014). Annual recorded offences for the latest calendar years (ANZSOC). Retrieved from http://nzdotstat.stats.govt.nz/wbos/Index.aspx?DataSetCode=TABLECODE7405

Straus, M. (2007). Conflict tactics scales. In Encyclopedia of Domestic Violence (pp. 190-197). New York, NY: Routledge.

Straus, M. A. (1979). Measuring intrafamily conflict and violence: The conflict tactics (CT) scales. Journal of Marriage and the Family, 41, 75-88. doi:10.2307/351733

Tannen, D. (1991). You just don't understand: Women and men in conversation. New York, NY: Ballantine.

Walker, L. (2009). The battered woman syndrome ( $3^{\text {rd }}$ ed.). New York, NY: Springer Publishing Company. 


\section{Appendix A}

\section{Potential Aspects of Stockholm Syndrome ${ }^{1}$}

1. Captive dissociates from her/his body in order not to feel the pain created by the captor

2. Captive finds self needing captor's [nurturance] numirance [SIC] and protection.

3. Captive feels intensely grateful to captor for kindness, however small, shown to her/him.

4. Captive is hyper vigilant to captor's needs to the neglect of her/his own needs.

5. Captive shows splitting (that is, dichotomous thinking).

6. Captive bonds to positive side of captor.

7. Captive dwells on kindness shown by captor while overlooking captor's violence against her/him.

8. Captive denies captor's violence against her/him and focuses on captor's positive side.

9. Captive denies own anger toward captor so that she or he may not even know that she or he is angry.

10. Captive sees captor as omnipotent.

11. Captive is "over compliant."

12. Captive puts captor's needs before her/his own and often does not know what her/his own needs are.

13. Captive sees herself/himself as "special" to captor.

14. Captive demonstrates the "salvation ethic"

\footnotetext{
${ }^{1}$ This list identifies characteristics observed in one or more "hostage" groups. As such, the characteristics are potential aspects of Stockholm Syndrome. Empirical research is needed to determine which are, in fact, aspects of Stockholm Syndrome and whether the composite of aspects observed in different 'hostage" groups are similar. All characteristics listed are viewed as responses to, not causes of, interpersonal abuse.
} 
15. Captive tries to control everyone in her/his environment, besides captor, to protect herself/himself from captor's violence.

16. Captive loves (cares for) captor even as she or he fears captor.

17. Captive feels closer to (and wants to be closer to) captor than to persons with whom she or he had or has a more mutually empowering relationship.

18. Captive takes captor's perspective, not her/his own. Captive may not even know what her/his perspective is.

19. Captive believes captor's violence toward her/him is deserved or caused by her/his own behaviour. She or he rationalizes captor's abuse.

20. Captive feels hatred for that part of her/him that captor said led to captor's abuse of her/him.

21. Captive feels shame for abuse done to her/him by captor.

22. Captive sees herself/himself as captor sees her/him: less valuable, less capable, and to blame for captor's problems as well as own problems.

23. Captive shows low self-esteem.

24. Captive is supersensitive to rejection.

25. Captive is depressed.

26. Captive has feelings of helplessness and powerlessness.

27. Captive shows ritualistic behaviours.

28. Captive is unable to recognize own feelings.

29. Captive displays anxiety reactions.

30. Captive is unable to concentrate.

31. Captive feels she or he is losing touch with reality.

32. Captive has physical and psychophysiological problems. 
33. Captive is distrustful of others.

34. Captive loses her/his own sense of self; sees herself/himself as captor sees her/him.

35. Captive feels she or he must have captor's favour or love to survive; appears emotionally dependent on captor.

36. Captive acts impulsively; loses internal control over own behaviour.

37. Captive is unable to make decisions.

38. Captive has a chameleon personality.

39- Captive expresses an idealized picture of her/his relationship with captor and loses touch with the reality of the relationship.

40. Captive resents outsiders' attempts to free her/him from captor.

41. Captive resents outsiders who point out her/his oppression by captor.

42. Captive demonstrates unresolved feelings regarding captor.

43. Captive develops sexual dysfunction (if relationship with captor becomes sexual).

44. Captive expects the same exploitation from others as she or he receives from captor.

45. Captive begins to have difficulty forming dose interpersonal relationships; shows psychological and physical withdrawal from others.

46. Captive finds it psychologically and emotionally difficult or impossible to physically leave or emotionally detach from captor, particularly if captor does not want her/him to leave.

47. Captive has difficulty maintaining boundaries between herself/himself and others.

48. Captive shows "push-pull" dynamics in relating with captor.

49 Captive shows "push-pull” dynamics in relating to others besides captor.

50. Captive has borderline personality characteristics.

51. Captive has difficulty keeping friends due to her/his "testing" them. 
52. Captive feels her/his relationship with captor is the most compelling relationship she or he has had.

53. Captive seeks to re-create intense feelings of captive-captor relationship in relationships with other persons besides captor.

54. Captive fears that captor will come back to get her/him even if captor is dead or in prison.

55. Captive becomes involved in other abusive relationships (besides that with captor) ${ }^{2}$

56. Captive is unable to feel warmth toward herself/himself and what she or he has been through.

57. Captive begins to feel overly responsible for outcome of relationships.

58. Captive is emotionally bonded with captor.

59. Captive displaces her/his anger at captor onto self and persons other than captor.

60. Captive identifies with the victim in the captor, projecting own victim status onto captor.

61. To account for captor's abusive behaviour, captive sees the captor as a victim and captor's abusive behaviour as resulting from captor being victimized.

62. Captive seeks to end captor's need to abuse through love, caring, kindness, etc. These efforts enable the captive to feel in control while a victim of another's uncontrollable abuse.

63. Captive experiences herself/himself as a childlike figure in relation to captor; responds to captor as to a parent figure.

64. Captive develops symptoms of ongoing trauma or, following release, Post- Traumatic Stress Disorder (PTSD).

\footnotetext{
${ }^{2}$ While we do not believe that this characteristic will be shown empirically to be an aspect of Stockholm Syndrome, it is included in this list as one which should nonetheless be subjected to empirical test due to on-going debate about the issue [SIC].
} 
65. Captor-captive relationship is sado-masochistic. (See Footnote 2)

66. Small kindnesses by captor create hope in captive that relationship with captor will get better. 


\section{Appendix B}

Stockholm Syndrome Scale (Graham et al., 1995)

\section{Core}

If I give my partner enough love, s/he will stop getting so angry at me I both love and fear my partner.

I do not want others to know how angry my partner gets at me.

There is something about me that makes my partner unable to control his anger.

My partner is as much a victim as I am.

The more I talk to people, the more confused I get about whether my relationship with my partner is healthy.

I know my partner is not a violent person; s/he just loses control.

The problem is not that my partner is "just an angry person"; it is that I provoke $\operatorname{him} /$ her.

\section{Psychological Damage}

I do not know who I am.

I feel down and blue.

I feel calm and sure of myself. (REVERSE CODED)

I feel good about who I am (REVERSE CODED)

I cannot make decisions.

I find it difficult to concentrate on tasks.

When others ask me how I feel about something, I do not know.

When I start getting close to people, something bad happens.

\section{Love Dependency}

I have to have my partner's love to survive

Without my partner, I have nothing to live for 
I need my partner's nurturance and protection to survive.

Without my partner, I would not know who I am

My partner's love and protection are more important than any hurt s/he might cause me.

If my relationship were to break up, I would feel so much pain that I would want to kill myself

In my eyes, my partner is like a god.

Relationship quality scale (Fletcher, Simpson, \& Thomas, 2000)

How satisfied are you with your relationship?

How committed are you to your relationship?

How intimate is your relationship?

How much do you trust your partner?

How passionate is your relationship?

How much do you cherish your partner?

Anxious attachment (Simpson, Rholes, \& Nelligan, 1992)

Others often are reluctant to get as close as I would like.

I often worry that my partner(s) don't really love me.

I worry about my partner(s) leaving me.

I often want to merge completely with others, and this desire sometimes scares them away.

I am confident that others would never hurt me by suddenly ending our relationship.

I usually want more closeness and intimacy than others do.

The thought of being left by others RARELY enters my mind.

I am confident that my partner(s) loves me just as much and I love them. 


\section{Attention Question}

Are you paying attention? If so, reply 'Extremely"

\section{Avoidant Attachment}

I find it relatively easy to get close to others.

I'm NOT comfortable having to depend on other people.

I'm comfortable having others depend on me.

I RARELY worry about being abandoned by others.

I don't like people getting too close to me.

I'm somewhat uncomfortable being too close to others.

I find it difficult to trust others completely.

I'm nervous whenever anyone gets too close to me.

Others often want me to be more intimate than I feel comfortable being.

Conflict tactics Inventory (Straus, 1979)

Threatened to hit or throw something at the other one (but not actually hit)

Threw or smashed or hit or kicked something (other than a person)

Threw something at partner

Pushed, grabbed or shoved the other one

Slapped the other

Kicked, bit, or hit with a fist

Hit or tried to hit with something

Beat up the other one

Threatened with a knife or gun

Used a knife or gun 